\title{
The amyloid precursor protein is a conserved Wnt receptor
}

\section{Tengyuan Liu ${ }^{1,2}$, Tingting Zhang 1,2, Maya Nicolas ${ }^{2,3,4 \dagger}$, Lydie Boussicault ${ }^{1}$, Heather Rice ${ }^{3,4 \ddagger}$, Alessia Soldano ${ }^{3,45}$, Annelies Claeys ${ }^{3,4}$, Iveta Petrova5, Lee Fradkin ${ }^{5}$, Bart De Strooper ${ }^{3,6}$, Marie-Claude Potier ${ }^{1}$, Bassem A Hassan ${ }^{1 *}$}

${ }^{1}$ Paris Brain Institute - Institut du Cerveau, Sorbonne Université, Inserm, CNRS, Hôpital Pitié-Salpêtrière, Paris, France; ${ }^{2}$ Doctoral School of Biomedical Sciences, Leuven, Belgium; ${ }^{3}$ Center for Brain and Disease, Leuven, Belgium; ${ }^{4}$ Center for Human Genetics, University of Leuven School of Medicine, Leuven, Belgium; ${ }^{5}$ Laboratory of Developmental Neurobiology, Department of Molecular Cell Biology, Leiden University Medical Center, Leiden, Netherlands; 'UK Dementia Research institute at University College London, London, United Kingdom
*For correspondence:

bassem.hassan@icm-institute.org

Present address: ${ }^{\dagger}$ School of Sciences and Engineering, The American University in Cairo, Cairo, Egypt; ${ }^{\ddagger}$ Department of Biochemistry and Molecular Biology, Oklahoma Center for Geroscience and Heathy Brain Aging, University of Oklahoma Health Sciences Center, Oklahoma, United States; $\S$ Laboratory of Translational Genomics, Department of Cellular, Computational and Integrative Biology (CIBIO), University of Trento, Trento, Italy

Competing interests: The authors declare that no competing interests exist.

Funding: See page 22

Received: 09 April 2021

Accepted: 01 September 2021

Published: 09 September 2021

Reviewing editor: Hugo J Bellen, Baylor College of Medicine, United States

(c) Copyright Liu et al. This article is distributed under the terms of the Creative Commons Attribution License, which permits unrestricted use and redistribution provided that the original author and source are credited.
Abstract The Amyloid Precursor Protein (APP) and its homologues are transmembrane proteins required for various aspects of neuronal development and activity, whose molecular function is unknown. Specifically, it is unclear whether APP acts as a receptor, and if so what its ligand(s) may be. We show that APP binds the Wnt ligands Wnt3a and Wnt5a and that this binding regulates APP protein levels. Wnt3a binding promotes full-length APP (fIAPP) recycling and stability. In contrast, Wnt5a promotes APP targeting to lysosomal compartments and reduces fIAPP levels. A conserved Cysteine-Rich Domain (CRD) in the extracellular portion of APP is required for Wnt binding, and deletion of the CRD abrogates the effects of Wnts on flAPP levels and trafficking. Finally, loss of APP results in increased axonal and reduced dendritic growth of mouse embryonic primary cortical neurons. This phenotype can be cell-autonomously rescued by full length, but not CRD-deleted, APP and regulated by Wnt ligands in a CRD-dependent manner.

\section{Introduction}

The Amyloid Precursor Protein (APP) is the precursor that generates the A $\beta$ peptide, whose accumulation is associated with Alzheimer's disease (AD; Selkoe and Hardy, 2016). As an ancient and highly conserved protein, APP and its homologs are found across animal species in both vertebrates and invertebrates (Shariati and De Strooper, 2013). As a result of the alternative splicing of the 18 exons coding for APP, there are three major isoforms expressed in different organs or tissues in mice and human (Panegyres and Atkins, 2011). APP695 is the major isoform expressed in the brain (Kang et alo, 1987). The expression of APP is detected at early stage during development (Ott and Bullock, 2001; Sarasa et al., 2000). In the developing mouse cortex, App mRNA is expressed continuously starting at embryonic day 9.5 (E9.5) coinciding with the initiation of neurogenesis and neuronal differentiation (Salbaum and Ruddle, 1994).

Structurally, APP is a type I transmembrane protein, which possesses a large extracellular amino acids sequence, an $\alpha$-helix transmembrane sequence and a relatively short intracellular $\mathrm{C}$-terminal sequence (Müller and Zheng, 2012; Coburger et al., 2013). Based on the architecture of the ectodomain, APP has been proposed to be a putative receptor (Ninomiya et al., 1993; Pietrzik et al., 2004; Hoe et al., 2009; Chen et al., 2006; Deyts et al., 2016). APP trafficking and processing have been intensively studied ever since the protein was first cloned. The turnover of transmembrane fulllength APP is rapid (Hunter and Brayne, 2012; El Ayadi et al., 2012), and internalised APP can be degraded in lysosome or processed by $\alpha-, \beta$-, and $\gamma$-secretase in different subcellular compartments 
to produce corresponding segments of APP. (Haass et al., 2012; Yuksel and Tacal, 2019). Recently, effort has been put into researching the function of the proteolytic products of APP under normal physiological condition (Coronel et al., 2018), as this may provide new clues for AD research.

During Drosophila brain development the fly homolog of APP, called APPL, functions as key component of the neuronal Wnt-PCP signaling pathway and regulates the axonal outgrowth in fly mushroom body (Soldano et alo, 2013). Both mammalian APP and fly APPL contain a Cysteine-Rich Domain (CRD) in the ectodomain of APP whose Cysteine distribution resembles that of the Wnt Tyrosine-protein kinase receptor Ror2 (Coburger et al., 2013; Oishi et al., 2003), suggesting the intriguing possibility that APP may itself be a receptor for Wnt family member.

Wnt signaling is an evolutionary conserved signal transduction pathway that regulates a large number of cellular processes. Three Wnt signaling pathway have been well described: the $\beta$-cateninbased canonical pathway, the planar cell polarity (PCP/Wnt) signaling pathway and the calcium pathway. Wnt signaling regulates various features during development such as cell proliferation, migration, and differentiation (Eisenmann, 2005). Recently, increasing evidence indicates that the Wnt signaling pathways are involved in the APP-related A $\beta$ production (Sellers et al., 2018; Elliott et al., 2018), but the precise mode of interaction between APP and the various Wnt pathways remains unclear.

The presence of CRD in APP, the reported involvement of Wnt signaling in APP processing and the importance of Wnt signaling during development suggested to us that APP may be a novel class of Wnt receptor regulating neuronal development. We used Drosophila and mouse embryonic primary cortical neurons as models to explore the APP-Wnt interactions during development. We provide evidence that the CRD of APP is a conserved binding domain for both canonical and PCP Wnt ligands. Furthermore, APP trafficking and expression is regulated by Wnts through the CRD, which in turn is required for APP to regulate axonal and dendritic growth and branching.

\section{Results}

\section{Drosophila APP like interacts genetically with Wnt5}

Drosophila APPL has been implicated in neural development (Cassar and Kretzschmar, 2016; Nicolas and Hassan, 2014) and is required for learning and memory (Preat and Goguel, 2016). Drosophila APPL is a homologue of human APP and has been used as a model for understanding the physiological function of the APP family (Soldano and Hassan, 2014; van der Kant and Goldstein, 2015). We previously reported that appl genetically interacts with components of the WntPCP pathway (Soldano et al., 2013) during mushroom body (MB) axon growth. The MBs are a bilateral neuronal structure in the fly brain required for learning and memory (Heisenberg, 2003). To understand the role of APPL in axonal PCP signaling, we first explored the specific nature of the genetic interaction between appl and the gene encoding the PCP protein Van Gough (Vang). In contrast to control MBs, $17 \%$ of male appl null mutant flies (appld/Y, henceforth Appl-/-) displayed a loss of the $\mathrm{MBb}$-lobe (Figure $1 \mathrm{~A}^{\prime} \mathrm{A}^{\prime}$ ). The PCP receptor $\mathrm{Vang}$ is also required for $\beta$-lobe growth (Shimizu et al., 2011); we observed that flies homozygous for the null allele vang ${ }^{\text {stbm- } 6}$ exhibited $50 \% \beta$-lobe loss. Whereas vang ${ }^{\text {stbm-6 }}$ heterozygotes show no MB defects, the loss of one copy of vang in Appl-/- flies is comparable (43\% $\beta$-lobe loss) to the complete loss of vang (Figure 1B). Therefore, in the absence of appl, vang is haploinsufficient. Next, we performed rescue experiments of Appl-/- mutant flies. Re-expression of APPL in the mutant MBs significantly rescued $\beta$-lobe loss. In contrast, the overexpression of Vang in Appl-/- null flies failed to do so. These loss and gain of function data suggest that Wnt-PCP signaling requires APPL to regulate axonal growth (Figure 1B).

APPL and Vang are both transmembrane proteins that are part of the same receptor complex required for MB axonal growth (Soldano et al., 2013). We wondered if APPL interaction with the Wnt-PCP pathway involved a ligand and focused on Drosophila Wnt5 as a candidate. Wnt5 has been implicated in the regulation of MB axon growth (van der Kant and Goldstein, 2015; Grillenzoni et al., 2007), although the mechanism is unclear. We first examined the genetic interaction between Wnt5 and vang in $\beta$-lobe axon growth. Loss of vang caused a highly penetrant phenotype (50\%), while Wnt5 nulls showed $\beta$-lobe loss only in $5 \%$ of the brains examined, suggesting that Wnt5 is largely dispensable for $\beta$-lobe growth. Surprisingly, Wnt5-/-; vang-/- double mutants showed an almost complete rescue of vang loss of function (Figure $1 C$ a,b,d,D, Supplementary file 1). 
A
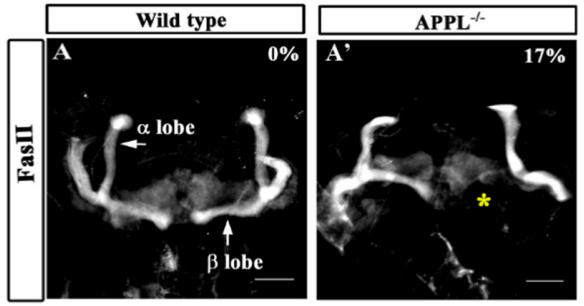

B

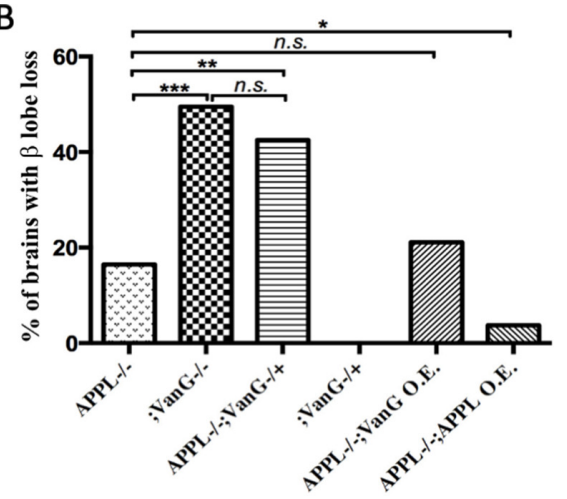

C

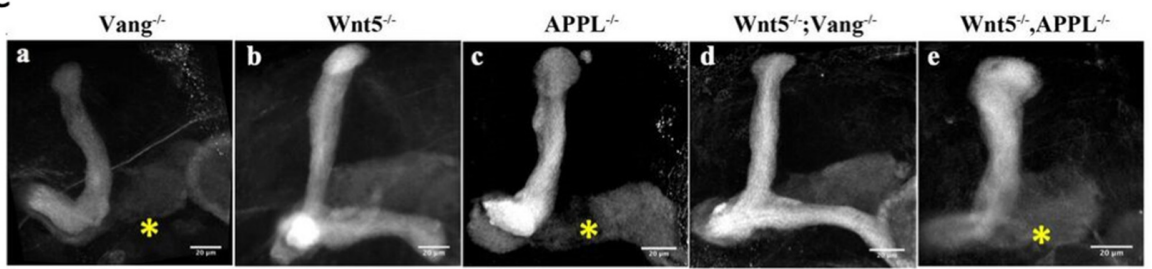

D

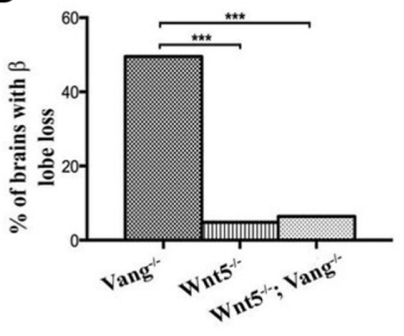

$\mathrm{E}$

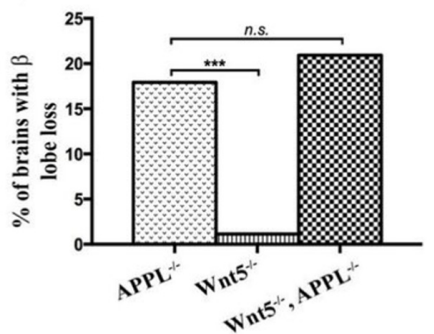

Figure 1. APPL mediates Wnt5a function in axonal growth. (A-A') Structure of the MB neurons in adult wild type and $\mathrm{APPL}^{-1-}$ mutant flies. Immunofluorescence using anti-Fascilinll (Fasll) antibody that labels the axons of the MB. (A) In wild type brains, the axons of the MB project dorsally to form the $\alpha$ lobe and medially to form the $\beta$ lobe. $\left(\mathrm{A}^{\prime}\right)$ In APPL null mutant flies (APPL ${ }^{d} / Y$ referred to as $\mathrm{APPL}^{-/}$), there is axonal growth defect of the $\beta$ lobe (as indicated by the asterisk) in $17 \%$ of the brains examined ( $n=97)$. Images are $z$-projections of confocal image stacks (scale bar, $50 \mu \mathrm{m}$ ). (B) APPL and VanG synergistically interact and APPL is necessary for VanG activity. The histogram shows the percentage of the $\beta$ lobe defect in different genetic backgrounds. The loss of $V$ ang induced a significantly higher penetrant phenotype up to $50 \%$, $(n=103)$ compared to $\mathrm{APPL}^{-1} ; \mathrm{p}$ value $=5.18^{-7}$ calculated with G-test. The loss of one copy of Vang in wild type background had no effect on axonal growth $(n=30)$. However, the removal of one copy of Vang in APPL ${ }^{-1}$ background significantly increased the phenotype to $43 \%$ $(n=47)$ compared to $\mathrm{APPL}^{-1} ; \mathrm{p}$ value $=0.001026$. The penetrance of the latter phenotype was not significantly different from the one observed in $\mathrm{Vang}^{-1} ; \mathrm{p}$ value $=0.4304$. While the overexpression of APPL rescued the $\mathrm{APPL}^{-1-}$ phenotype $(4 \%, n=54) ; p$ value $=0.01307$, the overexpression of Vang failed to $(21 \%, n=52) ; p$ value $=$ 0.4901. * Indicates a p value $<0.05$. Data are shown as median \pm whiskers. (Ca-e) Immunofluorescence analysis using anti-Fasll antibody to show the structure of the MB axons in adult mutant flies of the following genotypes: (a)

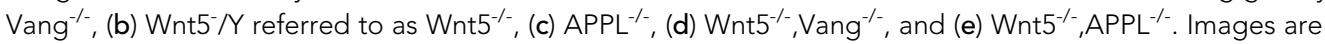
$z$-projections of confocal image stacks (scale bar, $20 \mu \mathrm{m}$ ). The asterisks correspond to the $\beta$ lobe loss phenotype. (D) Wnt5 inhibits axonal growth, after branching, independently of Vang. The Histogram shows the percentage of the $\beta$ lobe loss phenotype. Vang ${ }^{-/-}$flies exhibit a highly penetrant phenotype of $50 \%(n=104)$, while Wnt $5^{-/-}$flies show a significantly less penetrant phenotype $(5 \%, n=103) ; p$ value $=2.33^{-14}$ calculated with $\mathrm{G}$-test. The loss of Wnt5 rescued Vang loss of function $(6 \%, n=98) ; p$ value $=4.56^{-12}$. (E) Wnt5 inhibits axonal growth probably through APPL. Histogram showing the penetrance of the $\beta$ lobe loss phenotype. In APPL ${ }^{-1-}$ flies, $18 \%$ of the brains tested showed an axonal defect $(n=106)$. This percentage did not significantly change in the absence of both Wnt5 in $\mathrm{APPL}^{-1-}$ flies $(21 \%, \mathrm{n}=86)$; $\mathrm{p}$ value $=0.6027$. ${ }^{\star * *}$ indicates a $\mathrm{p}$ value $<1^{-5}$. 
Therefore, in the absence of Vang, Wnt5 inhibits $\beta$-lobe growth, suggesting that Wnt5 interacts with another receptor and antagonizes its function in PCP-mediated axon growth. We therefore examined the genetic interaction between Wnt5 and appl. Loss of Wnt5 in Appl-/- flies resulted in a phenotype similar to Appl-/- flies alone (Figure $1 C$ b,c,e, E). Thus, in the absence of APPL, Wnt5 no longer negatively impacts MB axon growth, suggesting that APPL may be a Wnt5 receptor.

\section{APPL and human APP bind Wnt5 via the CRD}

Wnt5 is a member of the large family of Wnt ligands, some of whose receptors and co-receptors harbor a conserved extracellular CRD thought to be important for Wnt binding (Dann et alı, 2001; Oishi et al., 2003). Intriguingly, APP harbors a CRD-like domain (Bush et al., 1993) in its extracellular region that includes 12 cysteine residues conserved across APP paralogs and orthologs (Figure 2A). The distribution of the cysteine residues resembles those present in the CRDs of other PCP receptors such as Fz and Ror-2 (Figure 2-figure supplement 1). We asked whether the CRDs of APP and APPL are potential Wnt5a-binding domains. To test this, we generated forms of human APP (hAPP) and APPL lacking the CRD (hAPP $\triangle$ CRD and APPL $\triangle$ CRD). Next, we overexpressed a tagged form of Wnt5a together with hAPP, APPL, hAPP $\triangle$ CRD, or APPL $\triangle$ CRD in HEK293 cells and

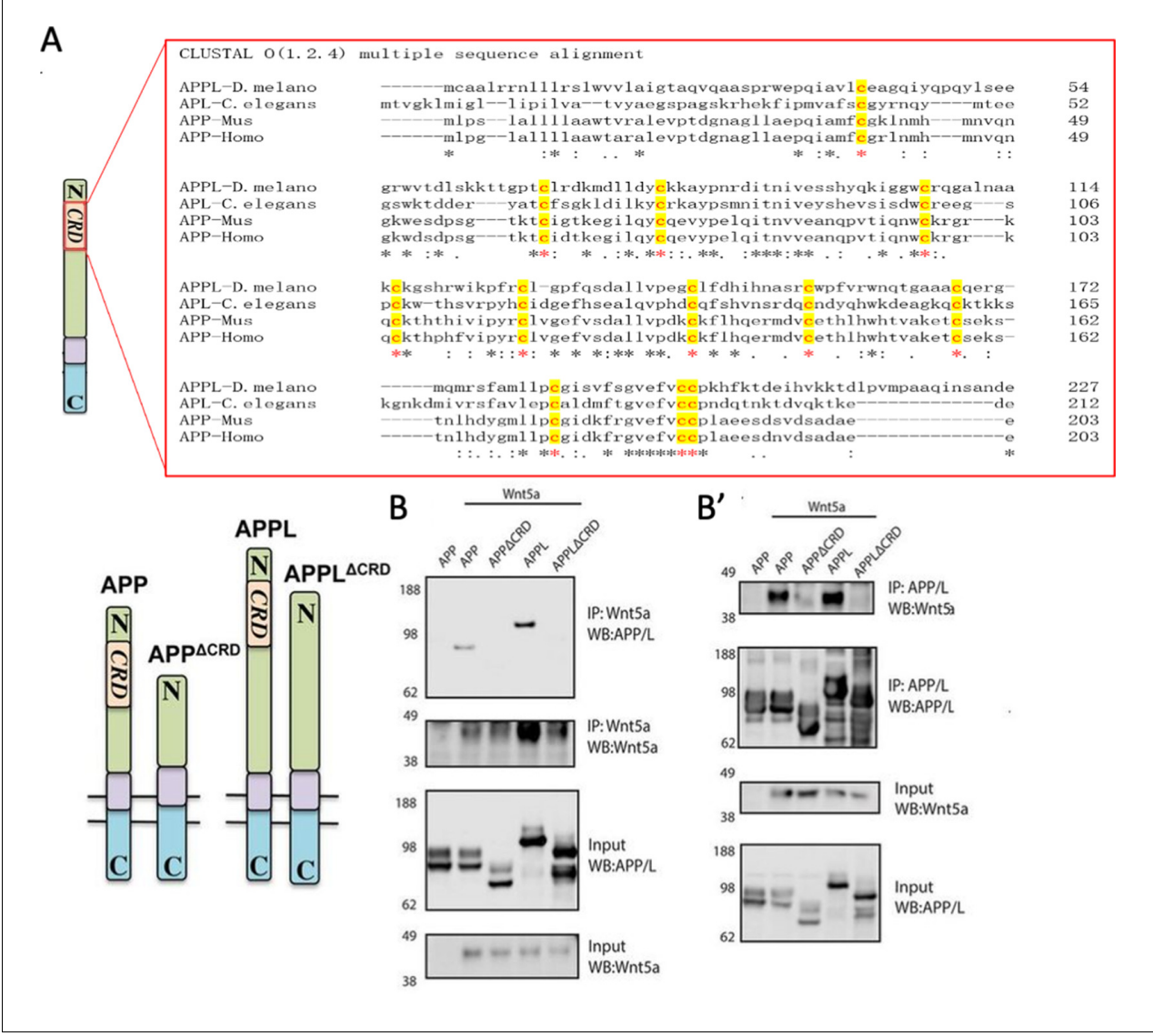

Figure 2. $A P P L$ and $W n t 5$ interact via the APP Cysteine-Rich Domain. (A) APPL extracellular region contains a conserved CRD. The figure shows a CLUSTAL alignment of the CRD of different APP homologs. The 12 cysteine residues (as indicated by the red asterisks) are highly conserved across species. (B-B') Wnt5a binds APPL and APP in a CRD-dependent manner. (B) Co-immunoprecipitation (co-IP) of the full-length proteins APP-flag and APPLflag but not their truncated forms $A P P^{\triangle C R D}$-flag and $A P P L^{\triangle C R D}$-flag with Wnt5a-myc. (B') Reciprocal co-IP showing that Wnt5a-myc is co-IPed with flAPP-flag and APPL-flag can but not when the CRDs are deleted. The online version of this article includes the following figure supplement(s) for figure 2 :

Figure supplement 1. PCP receptors harbor conserved Cysteine-Rich Domains (CRD).

Figure supplement 2. Co-immunoprecipitation assays reveal that Drosophila APPL binds to WNT5. 


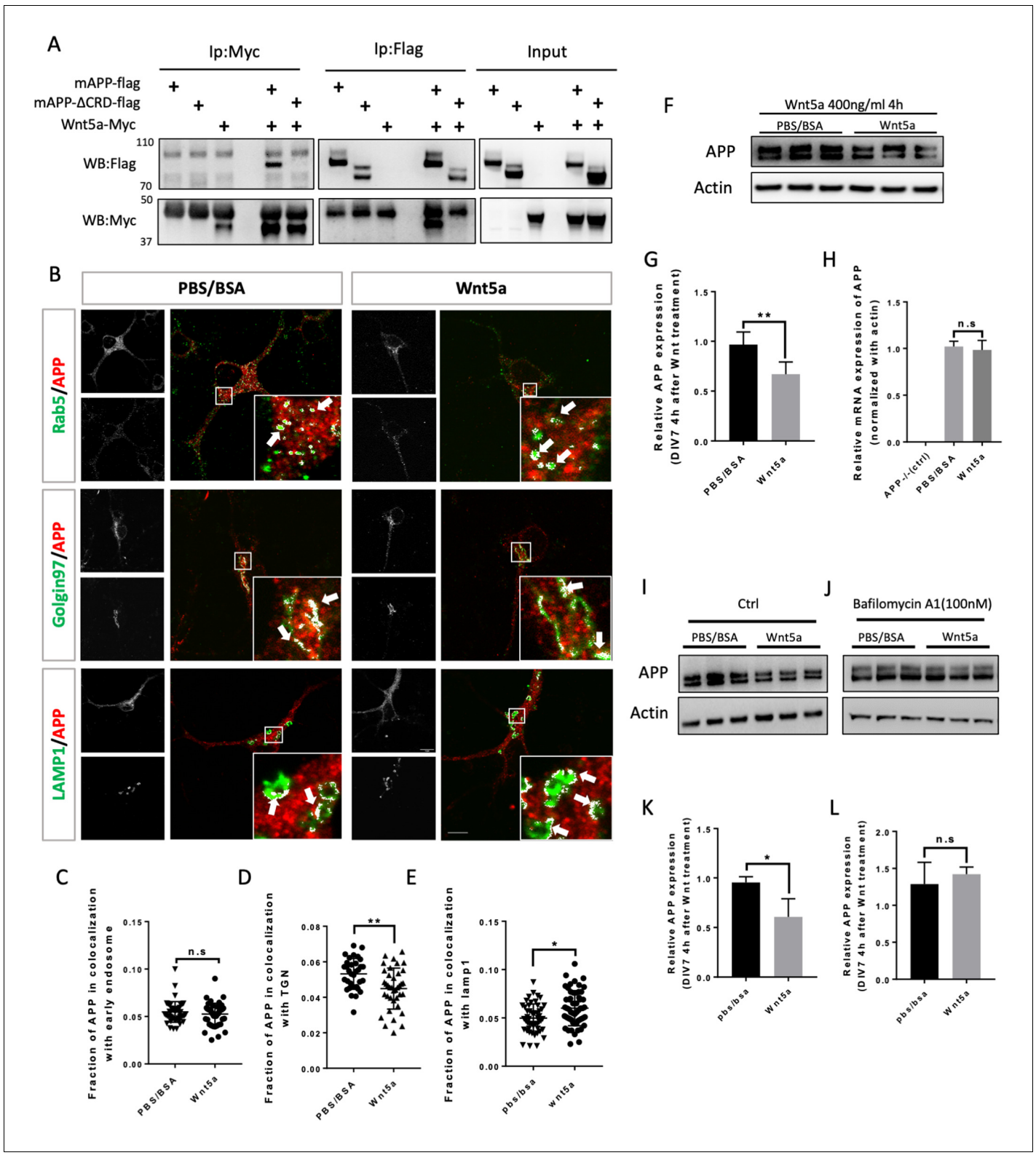

Figure 3. Wnt5a regulates APP expression through changing its intracellular trafficking. (A) Co-immunoprecipitation (co-IP) of Wnt5a-Myc with fulllength proteins mAPP-flag or mAPP-delatCRD-flag. The tagged proteins were co-expressed in HEK293T cells and immunoprecipitated with ant-flag and anti-Myc antibodies. Wild-type mAPP could pull down Wnt5a and vice versa, while mAPP lacking the CRD domain showed impaired ability to pull down Wnt5a, even with higher protein levels compared to wild-type mAPP in the input. (B) mAPP localization after 4 hr PBS/BSA or Wnt5a treatment. Immunofluorescence for APP (red), Rab5 (early endosome marker, green), Golgin97 (TGN marker, green), and Lamp1 (lysosome marker, green) revealed mAPP localization in different intracellular compartments. The inset showed zoomed in images of the area in the white box and arrows indicated the overlap of mAPP with respective cellular compartment markers. Scale bar $=10 \mu \mathrm{m}$. (C-E) Quantification of the overlap of mAPP with early endosome (C), TGN (D) or lysosome (E), respectively, after Wnt5a treatment. ( $n=33-55$ cells, t-test). (F) Western blots of mAPP and Actin on the lysates of DIV7 primary cultured cortical neurons showed that mAPP protein expression level was altered after Wnt5a treatment. (G) Quantification of the western blots results for fig F. ( $n=$ three biological independent repeat, t-test). (H) qPCR results showed that mApp mRNA expression was not affected after Wnt5a treatment on DIV7. App-/- mice derived primary neurons were used as a negative control. ( $\mathrm{n}=$ three biological independent repeat, one-way ANOVA). (I and J) Western blots for APP showed that the lysosome inhibitor Bafilomycin-A (J) could rescue Wnt5a-induced mAPP reduction compared with control groups (I). (K and L) Quantification of the western blots result for figure I and J. ( $n=$ three biological independent repeat, $t$-test). Bars represent the mean \pm S.E.M. Samples collected from at least two independent experiments. ${ }^{*} p<0.05,{ }^{* *} p<0.01$.

The online version of this article includes the following source data and figure supplement(s) for figure 3 :

Source data 1. Co-immunoprecipitation (co-IP) of Wnt5a-Myc with full-length proteins mAPP-flag or mAPP-delatCRD-flag. Source data 2. Western blots for mAPP and Actin after Wnt5a treatment on DIV7 primary cortical neurons.

Figure 3 continued on next page 
Figure 3 continued

Source data 3. Western blots for mAPP and Actin after Wnt5a treatment on DIV7 primary cortical neurons.

Source data 4. Western blots for mAPP and Actin after adding Bafilomycin followed by Wnt5a treatment on DIV7 primary cortical neurons.

Figure supplement 1. Rapid turnover of fl-mAPP in culture mouse primary cortical neurons.

Figure supplement 1-source data 1. Western blots for time course $(0.5 \mathrm{hr}, 1 \mathrm{hr}, 2 \mathrm{hr}, 4 \mathrm{hr})$ of fl-mAPP expression after Cycloheximide (50 $\mu \mathrm{g} / \mathrm{ml})$ treatment on DIV7 primary cortical neurons.

Figure supplement 1-source data 2. Western blots for time course (0.5 hr, 1 hr, 2 hr, $4 \mathrm{hr}$ ) of fl-mAPP expression after DMSO (0.05\%), treatment on DIV7 primary cortical neurons.

Figure supplement 2. APP overlap with early endosome, TGN and lysosome after Wnt3a/5a treatment.

Figure supplement 3. Wnt3a/5a treatment barely affect APP overlap with recycling endosome.

Figure supplement 4. Rab5 Golgin97 and Lamp1 expression after Wnt3a/5a treatment.

Figure supplement 4-source data 1. Western blots for fl-mAPP, Rab5, Golgin97, and Lamp1 after 4 hr of Wnt3a/5a treatment on DIV7 primary cortical neurons.

Figure supplement 5. Time course of $\mathrm{fl}$-mAPP after Wnt3a/5a treatment.

Figure supplement 5-source data 1. Representative western blots for the time course (0.5 hr, $1 \mathrm{hr}, 2 \mathrm{hr}, 4 \mathrm{hr})$ of fl-mAPP expression after PBS/BSA (ctrl) and Wnt3a/5a treatment at DIV7.

performed co-immunoprecipitation (IP) assays. Wnt5a immunoprecipitated full-length hAPP and APPL but not hAPP $\triangle$ CRD or APPL $\triangle$ CRD (Figure 2B). Reciprocally, full-length hAPP and APPL immunoprecipitated significant amounts of Wnt5a in contrast to hAPP $\triangle C R D$ and APPL $\triangle C R D$ (Figure 2B'). Similarly, APPL was found to precipitate Wnt5 from transfected Drosophila S2 cell lysates (Figure 2figure supplement 2).

\section{Wnt5a treatment affects APP trafficking and expression in maturing mouse primary cortical neuron}

The findings above suggest that the APP family may represent a new class of conserved Wnt receptors. We sought to investigate this further at a cell biological level using developing mouse embryonic primary cortical neurons as a model system. APP trafficking and processing have been intensively investigated in studies relating to $A D$, and according to early reports the half-life of APP is quite short, ranging from $1 \mathrm{hr}$ to $4 \mathrm{hr}$ (Hunter and Brayne, 2012; El Ayadi et al., 2012). In mouse embryonic (E16) primary neuron cultures, full-length mouse APP (fl-mAPP; henceforth we refer to mouse APP as mAPP and to human APP as hAPP) expression significantly dropped after $2 \mathrm{hr}$ of treatment with translational inhibitor (Cycloheximide) (Figure 3-figure supplement 1), suggesting relatively rapid turnover of mAPP. To study the relation between mAPP and Wnts, we first verified that mAPP also binds Wnt5a through its CRD and found that fl-mAPP but not mAPP $\triangle C R D$ co-IP's with Wnt5a, similar to APPL and hAPP (Figure 3A). Next, we used immunofluorescence to localize mAPP with or without Wnt5a treatment in developing cortical neurons during axonal outgrowth (DIV7). mAPP is modified to maturation in the Trans Golgi Network (TGN) to be subsequently transferred to the plasma membrane where it can be internalized into early endosomes. From the early endosome, mAPP is either recycled back to the TGN through retromer-dependent sorting, or to the late endosome and then lysosome to be degraded (Haass et al., 2012; Vagnozzi and Praticò, 2019). We used markers for early endosomes (Rab5), recycling endosome (Rab11), TGN (Golgin97), and lysosomes (Lamp1) to trace mAPP trafficking after $2 \mathrm{hr}$ and $4 \mathrm{hr}$ Wht5a treatment. The fraction of mAPP co-localized with early endosomes was not affected after $2 \mathrm{hr}$ (Figure 3-figure supplement 2A) or $4 \mathrm{hr}$ (Figure 3B,C) of Wnt5a treatment. Similarly, we observed no effects on co-localization with recycling endosomes (Figure 3-figure supplement $3 A, D$ ) indicating normal initial internalization and recycling of mAPP. However, we found a reduction of mAPP in the TGN, accompanied by an increase of mAPP in lysosomes both after $2 \mathrm{hr}$ (Figure 3-figure supplement 2D,G) and $4 \mathrm{hr}$ (Figure $3 B, D, E$ ) of Wnt5a treatment suggesting that Wnt5a regulates intracellular targeting of mAPP after internalization. Importantly, the levels of expression of these markers (Rab5, Golgin97, and Lamp1) are not affected by Wnt5a treatment (Figure 3-figure supplement 4). Next, we asked if this altered trafficking affected mAPP levels. We found that the level of fl-mAPP was significantly reduced after $4 \mathrm{hr}$ of Wnt5a treatment, as shown by western blot (Figure $3 F, G$ ), with no effect on mApp mRNA levels (Figure 3H). The results of immunofluorescence (IF) and western blot (WB) suggest that the decrease of the mAPP upon Wnt5a treatment is caused by lysosomal degradation. To 
A

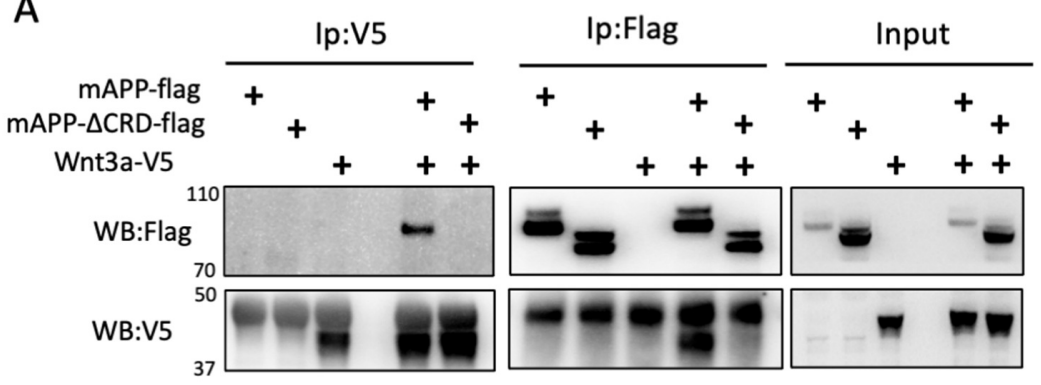

B
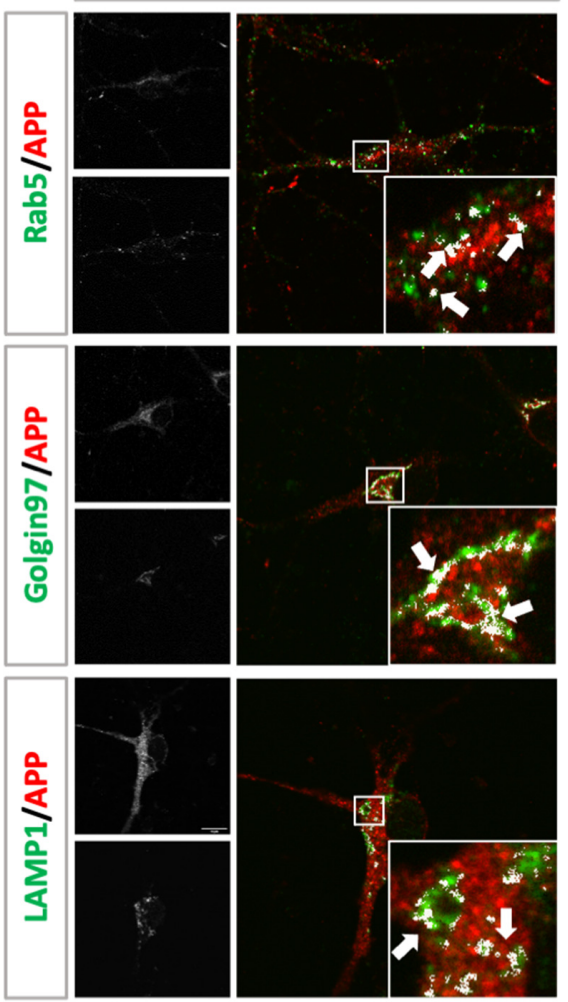

C

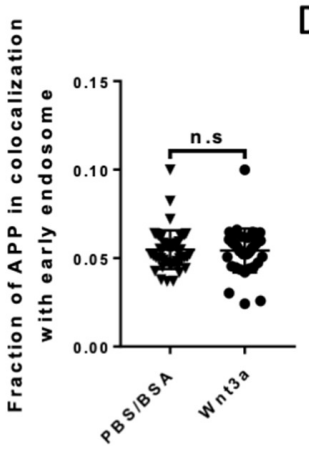

D

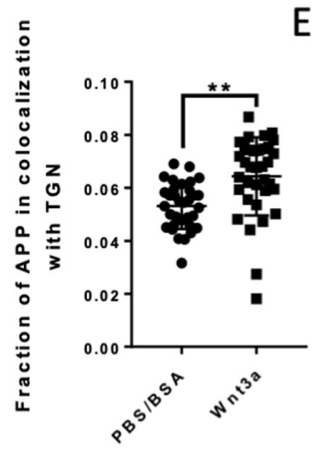

$E$
Wnt3a
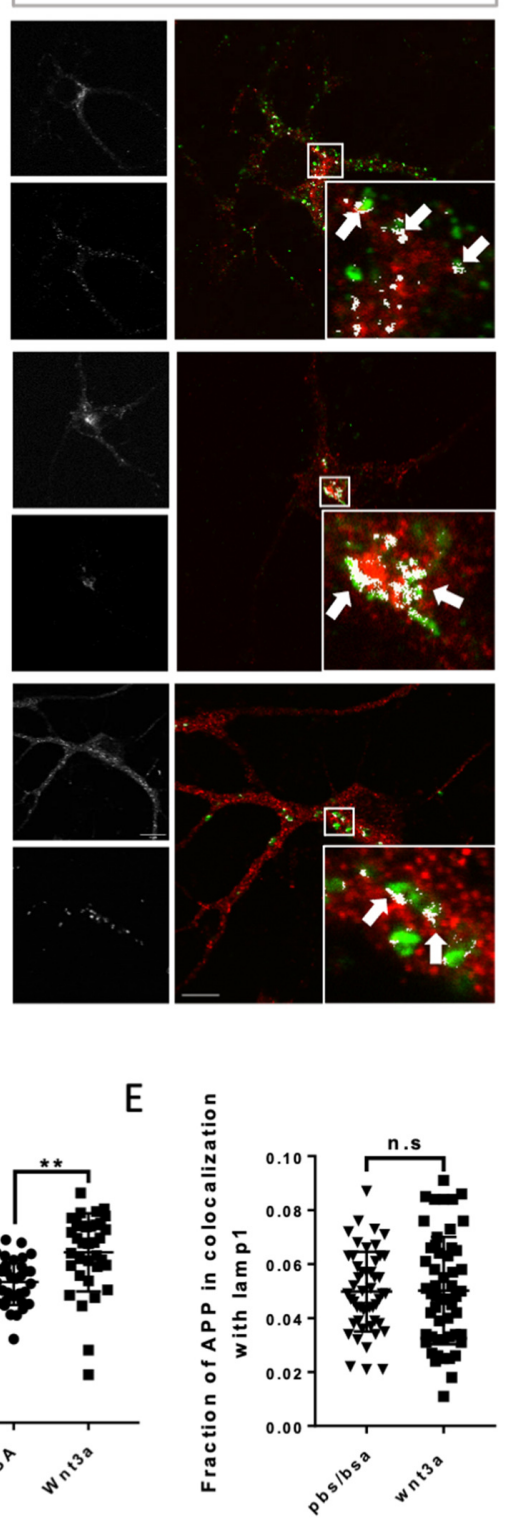

$\mathrm{F}$

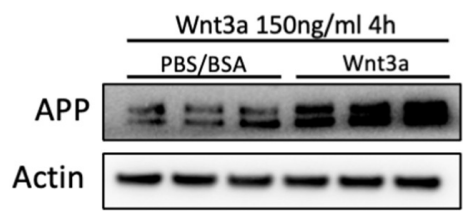

G

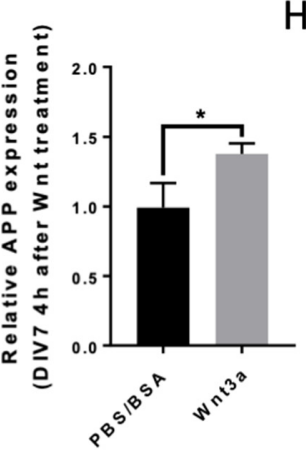

$\mathrm{H}$
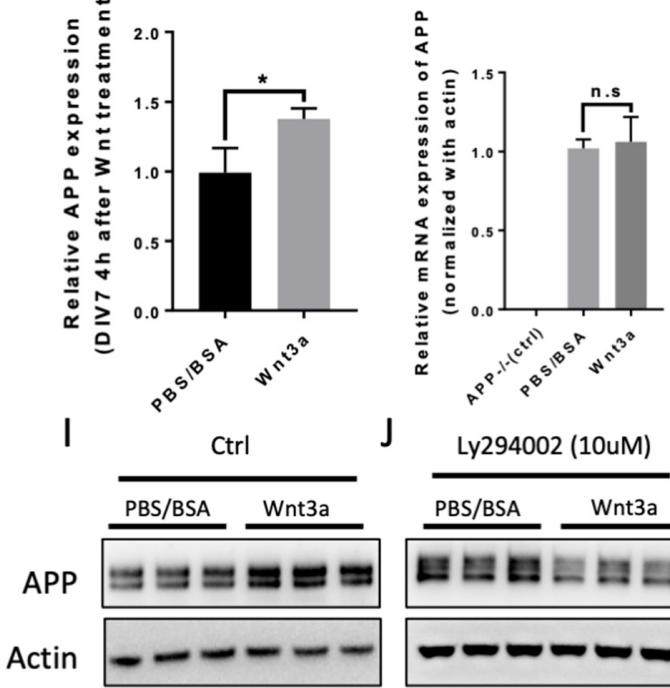

J Ly294002 (10uM)

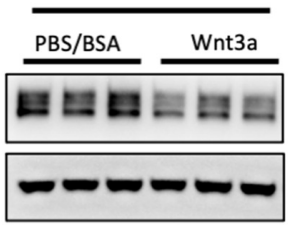

K
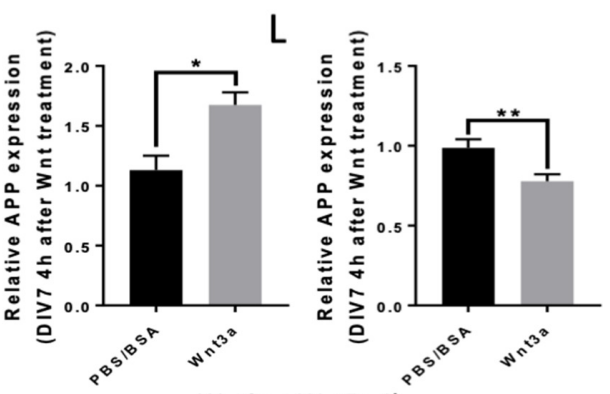

M

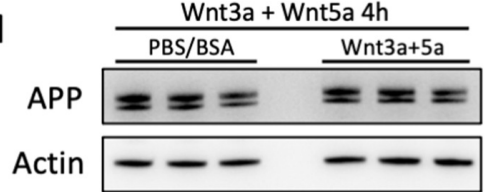

$\mathrm{N}$

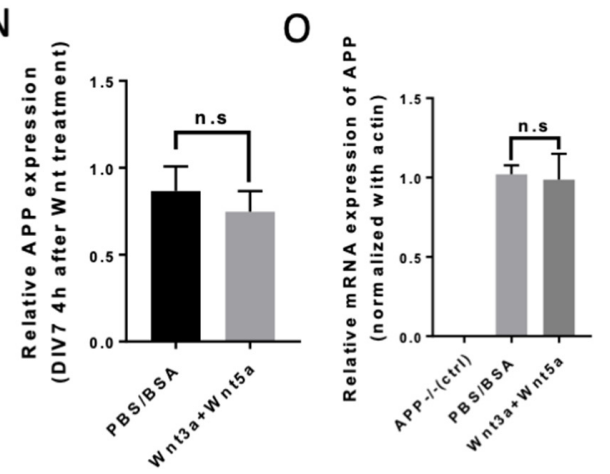

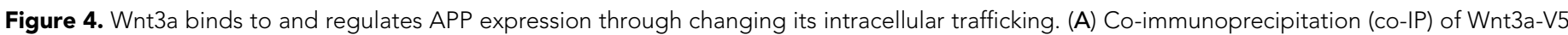

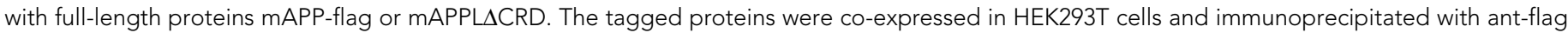

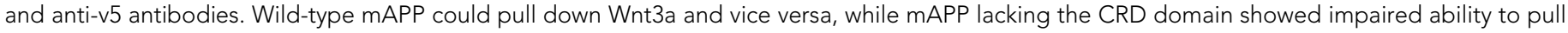
Figure 4 continued on next page 
Figure 4 continued

down Wnt3a even with higher protein levels compared to wild type mAPP in the input. (B) mAPP localization after 4 hr PBS/BSA or Wnt3a treatment. Immunofluorescence for APP (red), Rab5 (green), Golgin97 (green), and Lamp1 (green) revealed mAPP localization in different intracellular compartments. The inset showed zoomed in images of the area in the white box and arrows indicated the overlap of mAPP with respective cellular compartment markers. Scale bar $=10 \mathrm{um}$. (C-E) Quantification of the overlap of mAPP with early endosome (C), TGN (D) or lysosome (E), respectively, after Wnt3a treatment. ( $n=33-54$ cells, t-test). (F) Western blots of mAPP and Actin on the lysates of DIV7 primary cultured cortical neurons showed that mAPP protein expression level was altered after Wnt3a treatment. (G) Quantification of the western blots results for figure $F$. (n=three biological independent repeat, t-test). (H) qPCR results showed that mApp mRNA expression was not affected after Wnt3a treatment on DIV7. App-/- mice derived primary neurons were used as a negative control. ( $n=$ three biological independent repeat, one-way ANOVA). (I and J) Western blots for APP showed that the Retromer inhibitor Ly294002 (J) could rescue Wnt3a-induced mAPP increase compared with control groups (I). (K and L) Quantification of the western blots results for figure I and J. ( $n=$ three biological independent repeat, t-test). (M) Western blots for mAPP expression 4 hr after Wnt3a and Wnt5a treatment at the same time on DIV7. PBS/BSA group acted as control group. (N) Quantification of the western blots results for figure M. ( $n=$ three biological independent repeat, $t$-test). (O) qPCR results for mApp mRNA expression in mApp knockout neurons (negative control), PBS/BSA treated control group neurons and Wnt3a+Wnt5a-treated group neurons. ( $n=$ three biological independent repeat, one-way ANOVA). Bars represent the mean \pm S.E.M. Samples collected from at least two independent experiments. ${ }^{*} p<0.05,{ }^{* *} p<0.01$.

The online version of this article includes the following source data and figure supplement(s) for figure 4:

Source data 1. Co-immunoprecipitation (co-IP) of Wnt3a-V5 with full-length proteins mAPP-flag or mAPPL $\triangle$ CRD.

Source data 2. Western blots for mAPP and Actin after Wnt3a treatment on DIV7 primary cortical neurons.

Source data 3. Western blots for mAPP and Actin after Wnt3a treatment on DIV7 primary cortical neurons.

Source data 4. Western blots for mAPP and Actin after adding Ly294002 followed by Wnt3a treatment on DIV7 primary cortical neurons.

Source data 5. Western blots for mAPP and Actin after Wnt3a + Wnt5a treatment on DIV7 primary cortical neurons.

Figure supplement 1. APP affects beta-catenin expression after Wnt3a treatment.

Figure supplement 1-source data 1. Western blots for $\beta$-Catenin and Actin for APP-WT primary cultured cortical neurons after 4 hr of Wnt3a/5a treatment on DIV7 primary cortical neurons.

Figure supplement 1-source data 2. Western blots for $\beta$-Catenin and Actin for APP-KO primary cultured cortical neurons after 4 hr of Wnt3a/5a treatment on DIV7 primary cortical neurons.

Figure supplement 2. $A \beta$ detection after Wnts treatment on DIV7 primary cortical neurons.

confirm this, we used Bafilomycin-A in combination with Wnt5a treatment. Bafilomycin-A treatment was performed $1 \mathrm{hr}$ after Wnt5a addition as Wnt5a treatment already affected APP levels after $2 \mathrm{hr}$ (Figure 3-figure supplement 5)- to inhibit the lysosome and found that this restored mAPP to control levels (Figure 3I-L). These data suggest that non-canonical Wnt5a-PCP signaling reduces mAPP stability.

\section{Wnt3a binds to and stabilizes APP via the CRD}

We wondered whether mAPP can also bind other members of the Wnt family of ligands. Wnt3a is one of the 19 Wnt members in mouse and human. During development, Wnt3a usually induces $\beta$ catenin signaling pathway which plays an import role in gene expression, cell proliferation, and differentiation (Mulligan and Cheyette, 2012; Rosso and Inestrosa, 2013). Recent studies suggest that Wnt3a and beta-Catenin signaling may be involved in AD pathology (Parr et al., 2015; TapiaRojas et al., 2016). More interestingly, studies on mouse AD models showed that Wnt3a and Wnt5a interact competitively and antagonistically with regard to APP-mediated synapse loss (Sellers et al., 2018; Elliott et al., 2018). We therefore wondered whether, like Wnt5a, Wnt3a also binds to mAPP through the conserved CRD and regulates its levels. To test this, we performed IP experiments with Wnt3a. We found that fl-mAPP and Wnt3a co-IP in a CRD-dependent fashion (Figure 4A). We next tested the effects of Wnt3a treatment on APP trafficking. As shown in and Figure 3-figure supplement 2(A), The fraction of mAPP co-localized with early endosomes (Figure $4 B, C$ ) and recycling endosome (Figure 3-figure supplement 2A,D) was not affected after $2 \mathrm{hr}$ and $4 \mathrm{hr}$ of Wnt3a treatment. However, more mAPP was present in the TGN, with no effect on the lysosomal mAPP fraction after $2 \mathrm{hr}$ (Figure 3-figure supplement 2D,G) and $4 \mathrm{hr}$ (Figure 4B-E) of Wnt3a treatment. The expression levels of Rab5, Golgin97 and Lamp1 were not affected after Wnt3a treatment (Figure 3figure supplement 4). Western blot analysis showed increased fl-mAPP upon Wnt3a treatment (Figure 4F,G), but no effect on mRNA levels (Figure 4H). There is evidence that mAPP is recycled back to the TGN from early endosomes through the retrograde pathway (Vagnozzi and Praticò, 2019). To test whether Wnt3a regulates mAPP retro trafficking to the TGN, we co-treated primary neurons with Wnt3a and a retromer inhibitor (LY294002), retromer inhibitor treatment was 
A

pLv-pSyn1-MmAPP-Flag-IRESeGFP

PBS/BSA Wnt3a Wnt5a

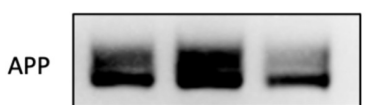

Actin

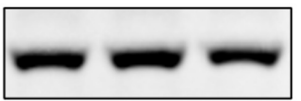

B

pLv-pSyn1-MmAPPdeltaCRD-Flag-IRESeGFP PBS/BSA Wnt3a Wnt5a

APP-deltaCRD

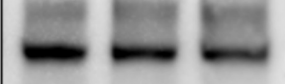

Actin

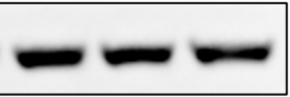

C

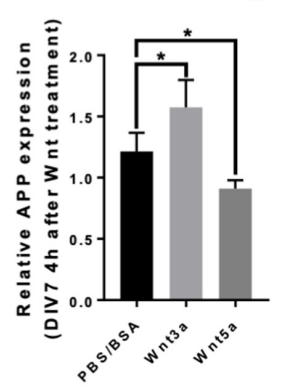

D

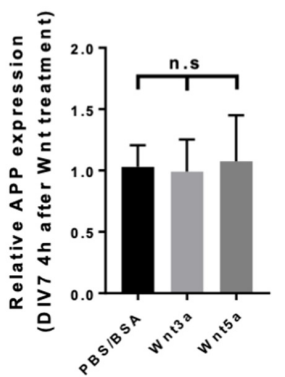

E
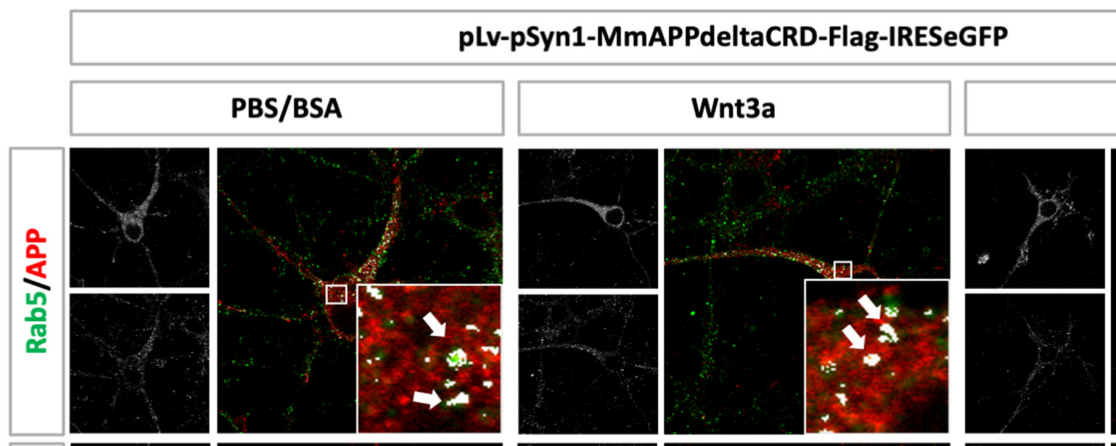

\section{Wnt5a}
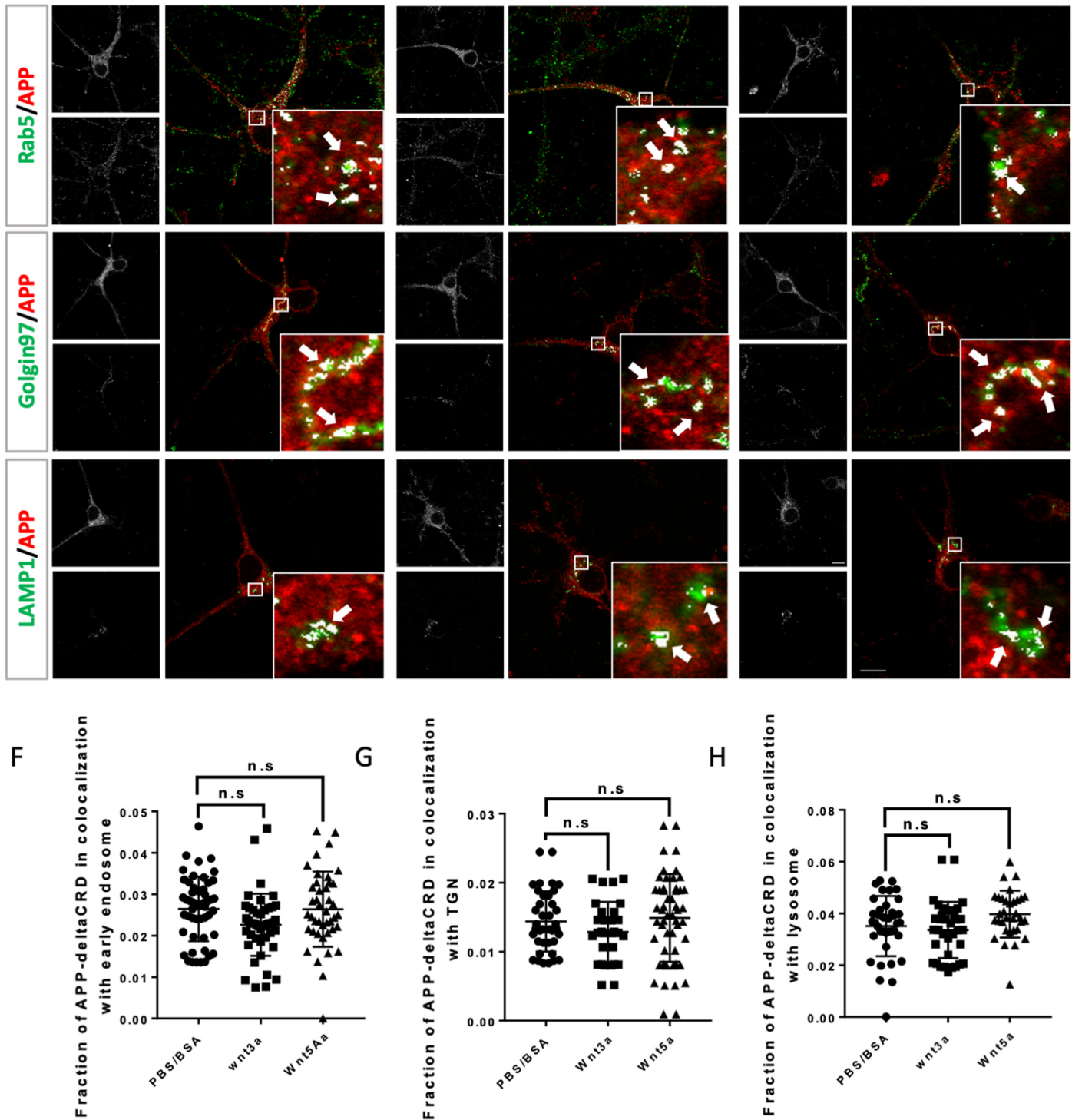

Figure 5. CRD is required for Wnt3a/5a to affect APP trafficking and expression. (A and B) Western blots for the detection of exogenous APP expression $4 \mathrm{hr}$ after PBS/BSA (control), Wnt3a or Wnt5a treatment at DIV7 in APP-KO primary cultured neurons which were transfected with pLv-pSyn1mAPP-Flag-IRESeGFP (A) or pLv-pSyn1-mAPPACRD-Flag-IRESeGFP (B) lenti-virus. (C and D) Quantification of the western blots results for figure A and $B$, respectively. ( $n=$ three biological independent repeat, one-way ANOVA). (E) Localization of exogenous mAPP expression in APP-KO primary cultured Figure 5 continued on next page 
Figure 5 continued

cortical neurons $4 \mathrm{hr}$ after Wnt3a or Wnt5a treatment. Immunofluorescence for APP (red), Rab5 (green), Golgin97 (green), and Lamp1 (green) revealed mAPP localization in different intracellular compartments. The inset showed zoomed in images of the area in the white box and arrows indicated the overlap of mAPP with respective cellular compartment markers. (F-H) Quantification of the overlap of mAPP with early endosome (F), TGN (G), or lysosome $(H)$, respectively, after Wnt3a or Wnt5a treatment. ( $n=32-51$ cells, one-way ANOVA). Bars represent the mean \pm S.E.M. Samples collected from at least two independent experiments. ${ }^{*} p<0.05$.

The online version of this article includes the following source data and figure supplement(s) for figure 5:

Source data 1. Western blots for APP and Actin after lenti-virus transduction followed by Wnt3a or Wnt5a treatment on DIV7 primary cortical neurons. Source data 2. Western blots for APP-deltaCRD and Actin after lenti-virus transduction followed by Wnt3a or Wnt5a treatment on DIV7 primary cortical neurons.

Figure supplement 1. Lenti-virus-induced exogenous mAPP expressed in mAPP knock out primary cortical neuron.

Figure supplement 1-source data 1. Western blots for flag and Actin after lenti-virus transduction on DIV7 primary cortical neurons.

Figure supplement 1-source data 2. Western blots for APP and Actin after lenti-virus transduction on DIV7 primary cortical neurons.

Figure supplement 2. Lenti-virus induced exogenous interact with Whts in mAPP knock out primary cortical neuron.

performed $1 \mathrm{hr}$ after Wnt3a addition as Wnt3a treatment could affected APP protein expression clearly $2 \mathrm{hr}$ later (Figure 3-figure supplement 5). This reversed the effect of Wnt3a on mAPP trafficking protein levels (Figure 4I-L). Then, we tested the effects of simultaneous treatment with Wnt3a and Wnt5a. This resulted in no change to APP protein levels compared to controls, suggesting that Wnt3a and Wnt5a neutralize each other's effects on mAPP (Figure $4 M, N$ ), again with no effects on mRNA levels (Figure 40). We and others have previously shown that APP is a key component in both Wnt canonical and non-canonical Wnt signaling (Elliott et al., 2018; Soldano et al., 2013). We confirmed this in our system and found that treatment with Wnt3a resulted in $\beta$-catenin accumulation in APP-WT, but not APP-KO, primary cortical neurons at DIV7 (Figure 4-figure supplement 1A-D). We also observed a tendency toward a decrease in $\beta$-catenin upon Wnt5a treatment, but this did not reach statistical significance.

Because Wnt treatment affects APP trafficking and expression, we tested $A \beta 40$ and A $\beta 42$ production in primary cortical neurons at DIV7 after $4 \mathrm{hr}$ treatment of with Wnt3a or Wnt5a. Our data show that a $4 \mathrm{hr}$ Wnt3a/5a treatment has a long-lasting effect on A $\beta 40 / 42$ production and that those effects are antagonistic. Consistent with Wnt3a favoring recycling of APP, we found that Wnt3a treatment significantly decrease $A \beta 40 / 42$ production (Figure 4-figure supplement $2 A, B$ ). In contrast, Wnt5a treatment, which induces APP internalization into acidic compartments, resulted in an increase in A $340 / 42$ production (Figure 4-figure supplement 2C,D). Importantly, these data are in accordance with other reports that Wnt/catenin pathway favors non-amyloidogenic APP processing while Wnt/PCP signaling does the opposite (Elliott et al., 2018).

Taken together, these data indicate that Wnt3a also binds to mAPP via the CRD and regulates mAPP trafficking and expression and that $\mathrm{Wnt5a}$ and $\mathrm{Wnt} 3 \mathrm{a}$ act antagonistically to regulate APP protein homeostasis.

\section{The CRD is required for Wnt-mediated regulation of APP trafficking and expression}

Our data thus far show that APP interacts with Wnts through its CRD and that Wnts regulate APP intracellular trafficking and expression. We therefore asked whether the CRD is required for the effects of Wnts on mAPP. To address this question, we created two lentiviral vectors: pLv-pSyn1mAPP-Flag-IRESeGFP (flag-tagged fl-mAPP) and pLv-pSyn1-mAPPACRD-Flag-IRESeGFP (flagtagged mAPP $\triangle C R D)$. Primary cortical neurons from App knockout mice were transduced with the flmAPP or mAPPACRD vectors, or a control GFP vector (pLv-pSyn1-IRESeGFP) exogenous APP/ APP $\triangle C R D$ was detectable using either anti-APP or anti-flag antibodies (Figure 5-figure supplement $1 A-C$ ). In neurons transduced with wild-type mAPP, we confirmed that mAPP expression could be increased and decreased by Wnt3a and Wnt5a treatments, respectively (Figure 5A,C). In contrast, in neurons transduced with mAPP $\triangle C R D$ those effects were eliminated (Figure 5B,D). Finally, we performed IF to trace mAPP and mAPP $\triangle$ CRD localization. Neurons transduced with wild type mAPP showed the same results as wild-type neurons with more mAPP in the TGN upon $4 \mathrm{hr}$ of Wnt3a treatment and more mAPP in lysosomes upon $2 \mathrm{hr}$ (Figure 3-figure supplement 2B,E,H) and $4 \mathrm{hr}$ of Wnt5a treatment (Figure 5-figure supplement 2A-D). Similarly, there was no effect on 


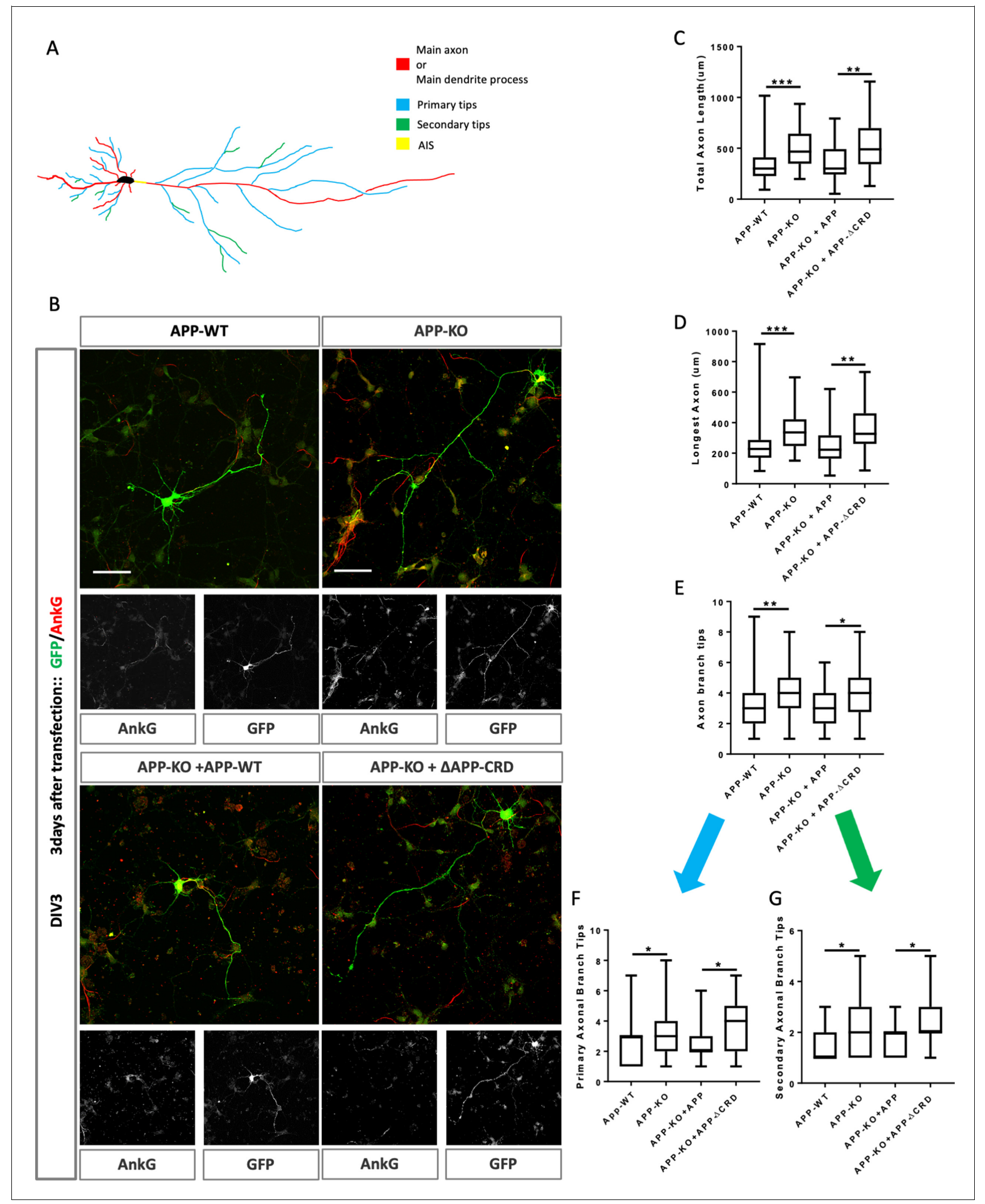

Figure 6. Cysteine-Rich Domain is critical for APP to regulate neurite outgrowth at DIV3. (A) Schematic of a primary neuron. Colored lines indicate axonal or dendritic branch tips which were quantified. Yellow indicates the Axon Initial Segment (AIS) marked with Ankry G in experiments. (B) Representative confocal images for GFP (green) and AnkG (red) immunostaining at DIV3 on primary cultured cortical neurons of the four genotypes examined: mAPP wild type, mAPP-KO, and mAPP-KO rescued with mAPP or CRD-mutant mAPP. Transfected plasmids containing GFP alone, mAPPFigure 6 continued on next page 
Figure 6 continued

flag-GFP or mAPP $\triangle$ CRD-flag-GFP, which was performed at the onset of cell seeding. Scale bar $=50 \mu m$. (C-E). Quantification of three parameters on these four genotypes at DIV3: the total axon length (the main axonal process and the branches deriving from the main process, $\mathrm{C}$ ), the longest axonal length (D), the total axonal branch tips (E), primary branch tips $(F)$ and secondary branch tips $(G)$. ( $n=59-70$ cells, one-way ANOVA). Bars represent the mean \pm S.E.M. Samples collected from at least two independent experiments. ${ }^{\star} p<0.05,{ }^{* \star} p<0.01{ }^{* \star *} p<0.001$.

The online version of this article includes the following figure supplement(s) for figure 6 :

Figure supplement 1. Neurite outgrowth is unaffected in APP knock out neurons at DIV2.

Figure supplement 2. Analysis of dendritic outgrowth and axon complexity index at DIV3.

colocalization with recycling endosome upon 2 or $4 \mathrm{hr}$ of treatment (Figure 3-figure supplement 3, E). All these effects were abolished in neurons transduced with mAPP $\triangle \mathrm{CRD}$ (Figure 5E-H; Figure 3-figure supplement 3F; Figure 3-figure supplement 2C, $F_{\text {, }} I$ ).

In summary, these data show that the CRD of mAPP is critical for Wnt3a/5a binding and mediates the effects of Wnts on mAPP trafficking and expression.

\section{CRD is critical for APP to regulate neurite outgrowth and complexity}

APP and its proteolytic products have been reported to affect neurite outgrowth during development (Billnitzer et alo, 2013; Young-Pearse et al., 2008) in different systems. We used primary cortical neuron derived from E16.5 mice embryos to investigate if the CRD of mAPP is required for regulation of neurite outgrowth by mAPP. We examined axonal and dendritic outgrowth (Figure 6A) at three developmental stages in vitro: DIV2, DVI3, and DIV7 (Dotti et alo, 1988).

While we found no effect on initial outgrowth at DIV2 (Figure 6-figure supplement 1A-F), at DIV3 mAPP knockout neurons exhibit increased axonal outgrowth compared to controls reflected in three parameters: total axon length, longest axon length, and the number of branch tips (Figure 6B-E). In contrast, dendritic outgrowth was not different from controls (Figure 6-figure supplement $2 \mathrm{~A}-\mathrm{C}$ ). We asked whether the CRD was required for mAPP function during neurite outgrowth. To this end, we transfected mAPP knockout neurons with either fl-mAPP or mAPP $\triangle C R D$. Increased axonal length and axonal branch tips were rescued by the fl-mAPP but not by the form lacking the CRD at DIV3 (Figure 6B-E). Next, we analyzed axonal branching in greater detail and found that loss of mAPP increased the numbers of both primary and secondary axonal branches at DIV3, an increase that was rescued by fl-mAPP but not by mAPP $\triangle C R D$ (Figure 6F, G). Finally, we examined the Axon Complexity Index (ACl) (Wong et alı, 2017), which measures the ratio of branches of different orders to total branch number, at DIV3. At this early stage, the $\mathrm{ACl}$ showed a tendency to increase in mAPP knockout neurons that was not significant (Figure 6-figure supplement 2D), likely because both primary and secondary branches show a similar level of increase. Together these data suggest an overall increase in axonal growth. In contrast to axonal growth, we found no significant alterations in dendritic length or branching (Figure 6-figure supplement 2EG) consistent with the fact that the spur in dendritic outgrowth is largely initiated at DIV4 (Polleux and Snider, 2010; Barnes and Polleux, 2009).

To further analyze neurite outgrowth, we examined axonal and dendritic growth at DIV7. By this stage, mAPP knockout neurons showed an increased $\mathrm{ACl}$ (Figure 7A,B). In contrast, total axonal length, longest axon length, and the total number of branch tips was not significantly different (Figure $7 C-E$ ). The increase in axonal complexity in mAPP knockout neurons was due to a significant reduction in the number of primary branches and a significant increase in the number of secondary branches (Figure 7F, G). Once again, all phenotypes were rescued by fl-mAPP but not mAPP $\triangle$ CRD.

Finally, we examined dendritic growth at DIV7. We observed no difference in total dendrite length or the size of the longest dendrite (Figure 7-figure supplement $1 A, B$ ), but observed a significant decrease in the total number of dendritic processes in mAPP knockout neurons compared to controls (Figure 7-figure supplement 1C). This reduction was due to the presence of fewer main dendritic processes in mAPP knockout neurons but no effect was observed on the primary or secondary dendritic branches (Figure 7-figure supplement 1D-F). All phenotypes were rescued by flmAPP but not mAPP $\triangle C R D$. Taken together, our results show that the role of APP in neuronal maturation requires the $C R D$ domain. 


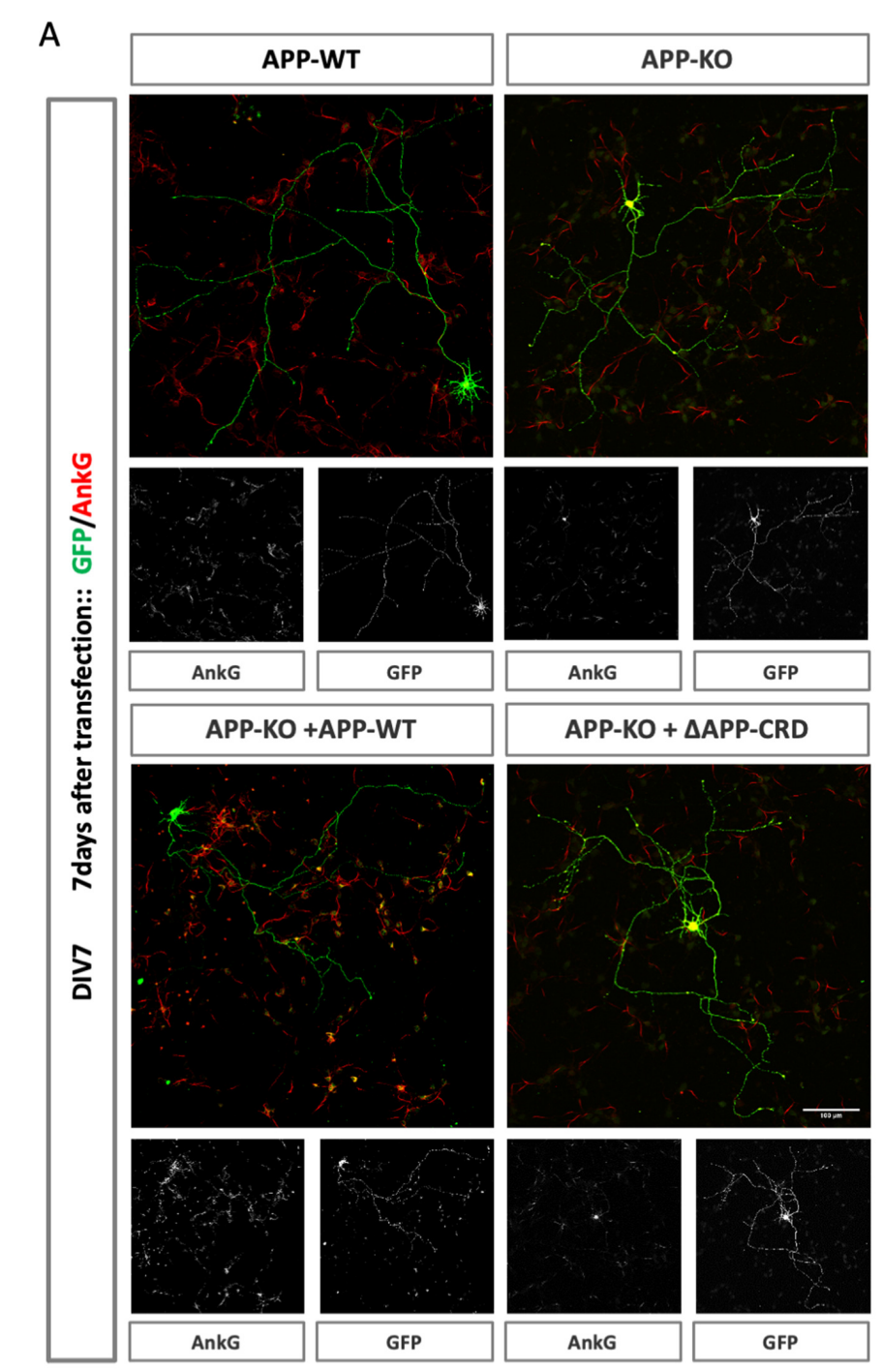

B

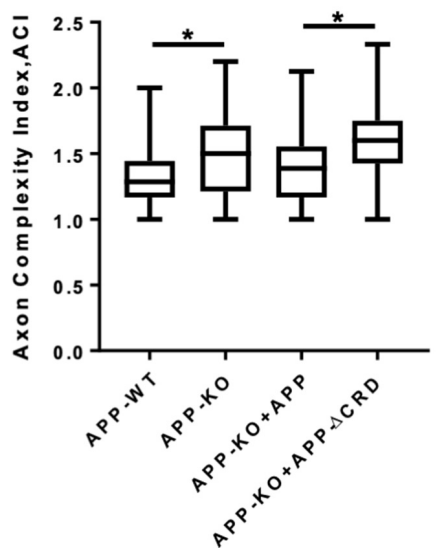

C
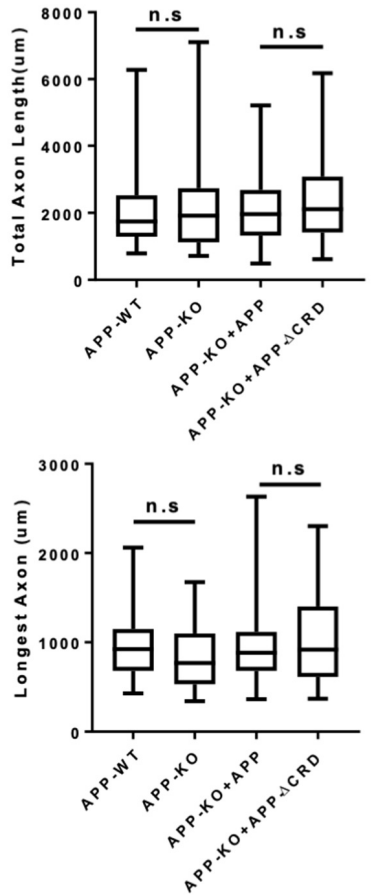

$\mathrm{E}$

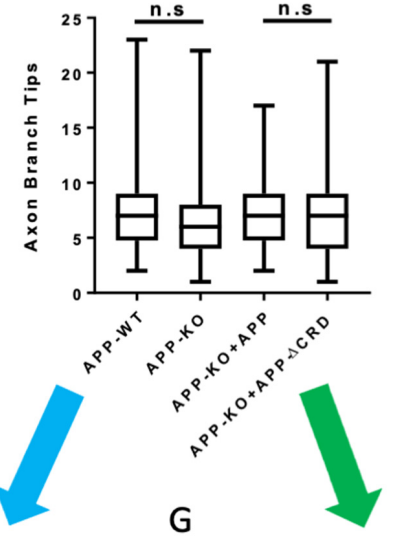

$\mathrm{F}$

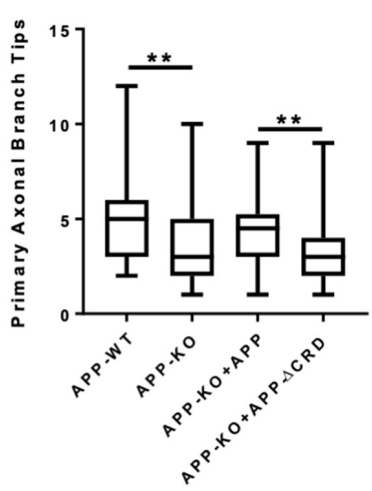

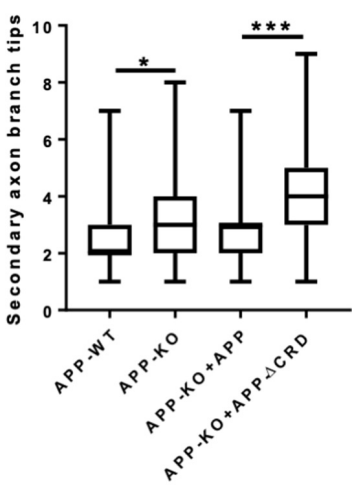

Figure 7. Cysteine-Rich Domain is critical for APP to regulate neurite outgrowth and complexity at DIV7. (A) Representative confocal images for GFP (green) and AnkG (red) immunostaining at DIV7 on primary cultured cortical neurons of the four genotypes examined: mAPP wild type, mAPP- KO and mAPP-KO rescued with APP or CRD-mutant APP. Transfected plasmids containing GFP alone, mAPP-flag-GFP or mAPP $\triangle$ CRD-flag-GFP, which was performed at the onset of cell seeding. Scale bar $=100 \mathrm{um}$. (B-G) Analysis of Axon complexity Index (ACl, B), the total axonal length (C), the longest Figure 7 continued on next page 
Figure 7 continued

axonal length (D), all axonal branch tips (E), the primary branch tips $(F)$ and the secondary branch tips $(G)$ at DIV7. ( $n=54$ cells, one-way ANOVA). Bars represent the mean \pm S.E.M. Samples collected from at least two independent experiments. ${ }^{*} p<0.05,{ }^{* \star} p<0.01,{ }^{* \star *} p<0.001$.

The online version of this article includes the following figure supplement(s) for figure 7:

Figure supplement 1. Outgrowth and complexity analysis of neurite at DIV7.

\section{Wnts regulate neurite development in a CRD dependent manner}

The Wnt pathway plays an important role in regulating neurite development, therefore we tested if the APP CRD is important for the interaction between APP and Wnt in regulating neurite outgrowth. To address this question, we analyzed neurite outgrowth in APP-KO primary cortical neurons rescued with APP-WT or APP- $\triangle$ CRD plasmids after Wnt3a/5a treatment. On DIV3 Wnt3a treatment significantly increased total axon length, the length of longest axon and axon branch tips in the presence of $\mathrm{fl}-\mathrm{APP}$ but not APP- $\Delta$-CRD (Figure $\mathbf{8 A}, \mathrm{B}, \mathrm{C}$ ). These data suggest that APP mediates Wnt3a effects on axonal outgrowth. In contrast to Wnt3a, Wnt5a treatment had no effect in the presence of fl-APP but resulted in increased axonal length when the CRD domain was removed. These data show that APP normally protects axons from the effects of Wnt5a at this developmental stage and that the CRD is required for this (Figure 8B). Thus, APP promotes Wnt3a and antagonizes Wnt5a effects on neurons at DIV3 via the CRD domain. Similarly, on DIV7 we found a positive Wnt3a effect on axon complexity which was observed in the presence of fl-APP but not APP- $\Delta$-CRD (Figure 8D). In contrast Wnt5a had no effect. Finally, we found that treatment with either Wnt3a or Wnt5a decreases the number of the main dendrites in the presence of fl-APP and the effect is absent or even reversed in the presence of APP- $\triangle$-CRD (Figure 8E). Together, these data show that the CRD of APP is required for Wnt3a/5a to regulate neurite outgrowth in cortical primary neurons.

\section{Discussion}

Here, we identify a previously unknown conserved Wnt receptor function for APP proteins. We show that APP binds both canonical and non-canonical Wnt ligands via a conserved CRD and that this binding regulates the levels of full-length APP by regulating its intracellular trafficking from early endosomes to the trans Golgi network versus the lysosome. Finally, we show that APP through the CRD regulates neurite growth and axon branching complexity in primary mouse cortical neurons.

A function for APP as a cell surface receptor has be proposed for quite a long time (Kang et al., 1987). The first strong evidence came from the structure of APP which shares similarity with type I transmembrane receptors. For example the growth factor like domain (GFLD) in the E1 region of APP could act as a ligand-binding site, and disulfide bridges within the same E1 area could further facilitate ligand-induced signal transduction by stabilizing the structure of APP ectodomain (Reinhard et alı, 2005; Rossjohn et al., 1999; Stahl et al., 2014; Kaden et al., 2009). In addition, the site-specific proteolytic processing property of APP resembles several membrane receptors and constitute a second line of evidence. For instance, both APP and Notch are processed by $\gamma$-secretase and release the intracellular domain AICD and NICD, respectively, to induce transcriptional activity by nuclear transfer of the ICDs (Chang et al., 2006; Ables et al., 2011). Several putative ligands have been proposed including proteolytic products of APP itself. Interestingly, a conserved CRD within the E1 region of APP makes APP a putative Wnt receptor as the CRD is required for the binding between Wnt and its receptor and co-receptor like Frizzled Ror-2 and Musk (Niehrs, 2012), although the crystal structure of the APP CRD is different from that of classic Wnt receptors. In this study, using immunoprecipitation we have shown that mouse APP binds in a CRD-dependent manner to Wnt3a and Wnt5a the two well-known ligands for triggering canonical or non-canonical Wnt signaling pathways, respectively. Based on these data, we speculate that APP might act as a conserved Wnt receptor as its CRD is highly conserved across species, and that the binding may not be limited to Wnt3a or Wnt5a, but also apply to all other Wnt family members. As Wnt signaling is critical for development and tissue homeostasis, the role of APP as a component or putative receptor or co-receptor in Wnt signaling should be carefully studied. The difficulty to explore the exact role of APP may not only come from the complexity of Wnt signaling, but also from the structural properties of APP itself. For example, the extracellular domain of APP harbors several binding site for the 
A
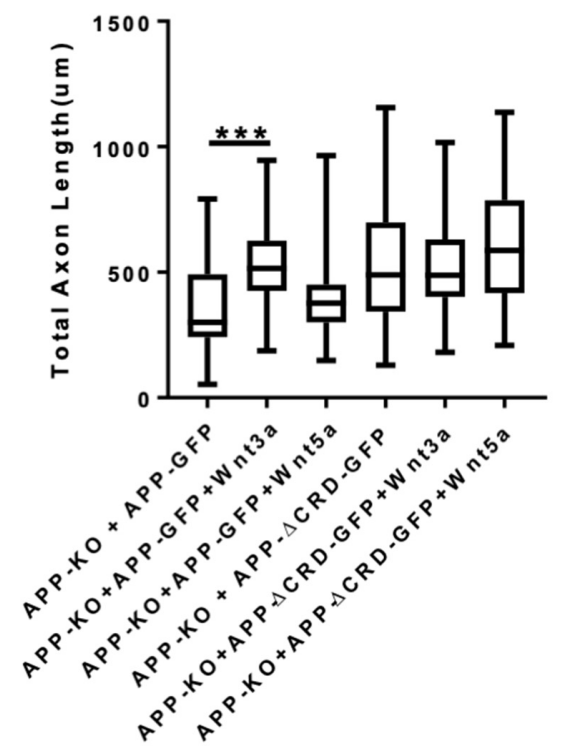

B

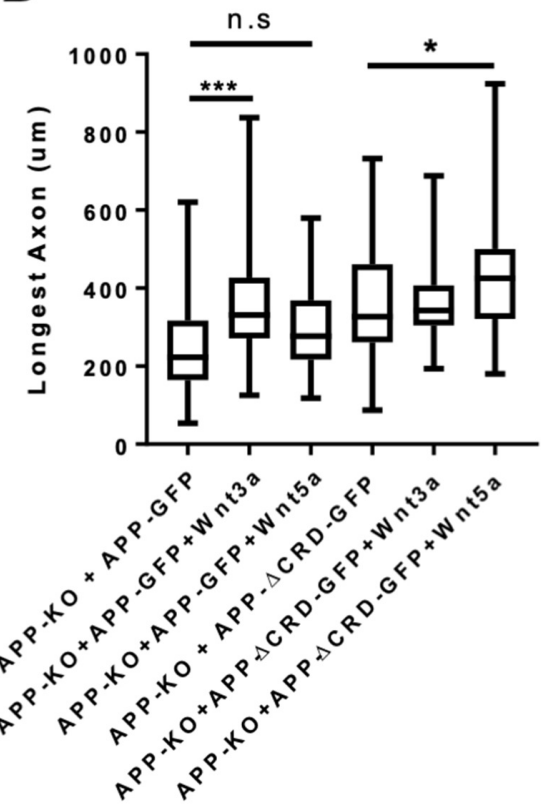

C

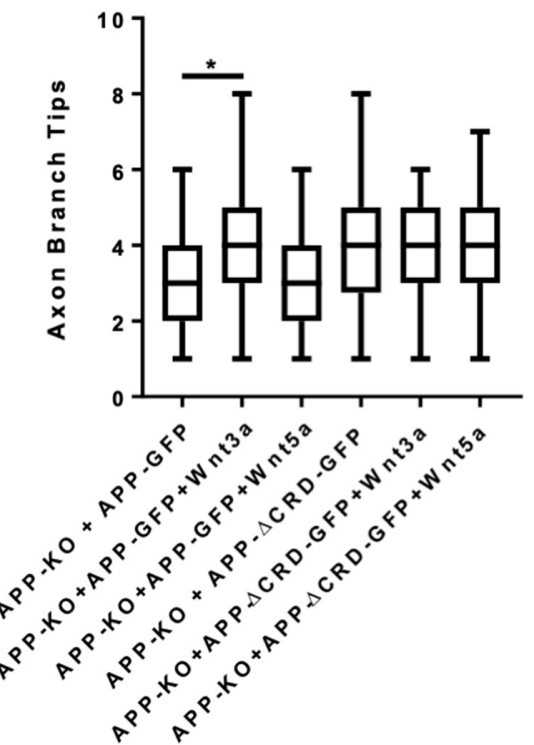

\section{Effection of Wnts treatment on neurite outgrowth at Div7 primary cortical neurons}

D

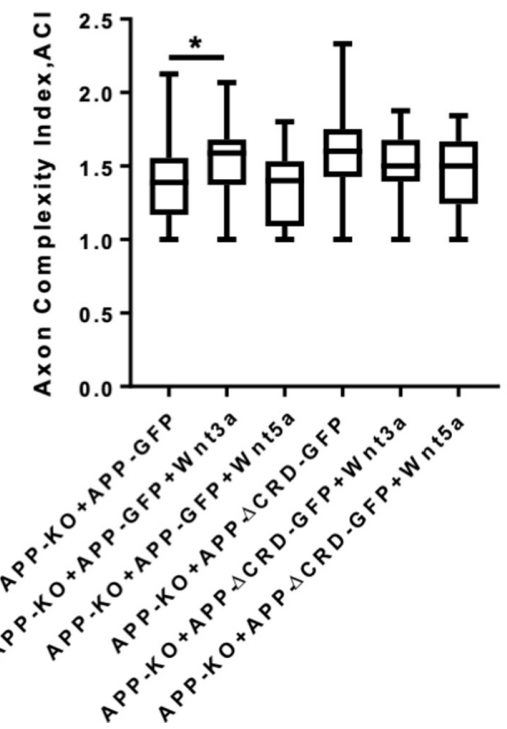

$\mathbf{E}$

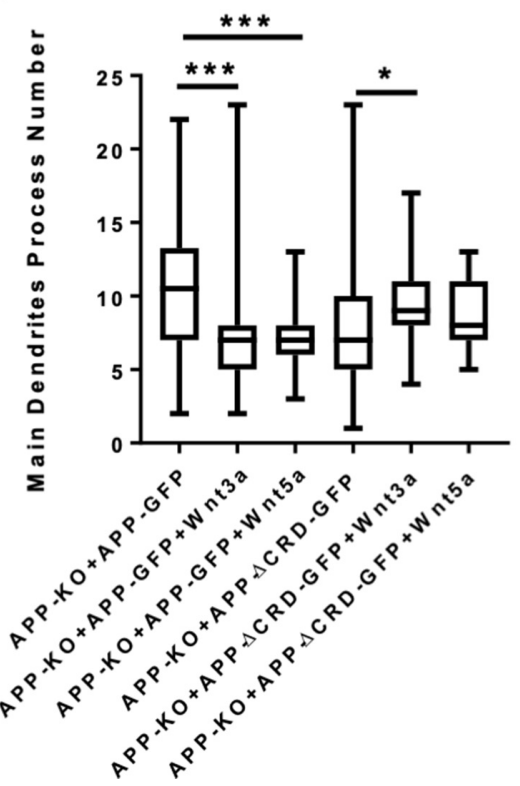

Figure 8. Neurite outgrowth analysis at DIV3 and DIV7 after Wnts treatment. (A-C) Quantification of total axon length (A), the longest axon length (B), and axon branch tips (C) from DIV3 cultured APP-KO primary cortical neuron after Wnts treatment rescued with APP-WT or APP- $\triangle$ CRD, respectively. ( $n=46-63$ cells, one-way ANOVA). (D and E) Analysis of axon complexity (D) and the main dendritic process number (E) from DIV7 cultured APP-KO primary cortical neuron after Wnts treatment rescued with APP-WT or APP- $\triangle C R D$, respectively. ( $n=47-54$ cells, one-way ANOVA). Bars represent the mean \pm S.E.M. Samples collected from at least two independent experiments. ${ }^{\star} P<0.05,{ }^{\star \star \star} p<0.001$.

molecules in the extracellular matrix (ECM), such as the Heparin binding domain (HBD) is not only exist in E1 area a second HBD has been found in the E2 region (Deyts et al., 2016). A recent study has shown that LRP6, the co-receptor of canonical Wnt signaling, could directly bind to APP 
(Elliott et al., 2018). Using peptide Mapping array this group further revealed several binding sites (20-70 amino acids in length) in the ectodomain of APP, and one of the sites (34 amino acids) is located within the APP CRD. Based on our IP results indicating a Wnt receptor function for APP, an obvious question arises as to whether LRP6 and APP compete for Wnt. Before trying to address this problem, several issues need to be resolved. First, as in our IP experiments the whole CRD (150 amino acids) was deleted it is not clear if specific sequences inside the CRD are critical for Wnt binding that may or may not overlap with the reported LRP6-binding site. A second important point is that the results of the peptide mapping array may not reflect the exact binging site for LRP6 as these short synthesized peptides may lack information embedded in the 3D structure like the disulfide bridges formed by Cysteines that may be critical for maintaining the stability of the APP extracellular domain (Rossjohn et al., 1999; Stahl et al., 2014). Significant further biophysical and biochemical analysis is required to understand the details of the interaction and various components of the Wnt receptor complex.

APP has been extensively reported to be involved in regulating neurite outgrowth (Billnitzer et al., 2013; Young-Pearse et al., 2008; Araki et al., 1991; Southam et al., 2019; Small et al., 1994; Perez et al., 1997), with conflicting conclusions as to whether APP promotes or inhibits neurite outgrowth. In our experiments, we found that while in Drosophila APPL loss reduced axonal growth, the comparison of axonal outgrowth and branching in primary cortical neuron derived from mAPP wild type or mAPP knock out mice at DIV2, DIV3 and DIV7 showed that loss of mAPP significantly accelerated axonal maturation. Specifically, we found that the initial phase of axonal growth at DIV2 is unaffected, but that APP mutant axons grow longer at DIV3 and then show increased axon complexity at DIV7. We therefore suggest that the conflicting data in the literature may arise from examining different types of neurons at different time points, where the requirement of APP may differ in a context-specific manner. We speculate that this context specificity may in part be due to the levels and types of Wnt ligands present in the environment.

Finally, our findings suggest that in addition to the well-described proteolytic processing of APP, the regulation of its recycling by Wnt ligands may be crucial for its function. It is important to note that, like proteolytic processing, Wnt ligands regulate APP stability post-translationally, as we found no effect on App mRNA levels upon Wnt treatment. With regard to the role of APP processing in Alzheimer's disease, recently published work suggests that an imbalance between Wnt3a/canonical signaling pathway and the Wnt5a/PCP signaling pathway at the initial step of amyloid beta production could trigger a vicious cycle favoring the amyloidogenic processing of APP (Sellers et al., 2018; Elliott et al., 2018). Our findings that Wnt3a and Wnt5a have opposite effects on amyloid beta production provide a mechanistic framework for understanding how the normal physiological function of APP directly impacts the generation of a key marker of AD, and thus potentially links the normal activity of APP to its role in neurodegeneration. Whether and how the modulation of APP's role in Wnt signaling may offer future therapeutic avenues for $A D$ is an exciting venue for future research.

\section{Materials and methods}

Key resources table

\begin{tabular}{lllll}
$\begin{array}{l}\text { Reagent type (species) } \\
\text { or resource }\end{array}$ & Designation & Source or reference & Identifiers & Additional information \\
\hline Antibody & $\begin{array}{l}\text { Mouse monoclonal } \\
\text { anti-Fasll } \\
(1 \mathrm{D} 4)\end{array}$ & $\begin{array}{l}\text { Developmental Studies } \\
\text { Hybridoma Bank (DSHB) }\end{array}$ & $\begin{array}{l}\text { AB_528235 } \\
\text { RRID:AB_528235 }\end{array}$ & IF (1:50) \\
\hline Antibody & $\begin{array}{l}\text { Rabbit polyclonal } \\
\text { anti-Wnt5a }\end{array}$ & Cell Signaling & Cat\# 2392 & WB (1:1000) \\
& $\begin{array}{l}\text { Rabbit polyclonal } \\
\text { anti-GFP }\end{array}$ & Invitrogen & Cat\# A-11122, & IF (1:500) \\
\hline Antibody & Rabbit polyclonal & & RRID:AB_221569 & IF (1:100) \\
\hline Anti-APP & Synaptic Systems & Cat\# 127 003 & RRID:AB_2056967 WB (1:1000) \\
\hline Antibody & Mouse monoclonal & Synaptic Systems & Cat\# 108 011 & IF (1:100) \\
& anti-rab5 & & RRID:AB_887773 & WB (1:1000) \\
\hline
\end{tabular}

Continued on next page 
Continued

\begin{tabular}{|c|c|c|c|c|}
\hline $\begin{array}{l}\text { Reagent type (species) } \\
\text { or resource }\end{array}$ & Designation & Source or reference & Identifiers & Additional information \\
\hline Antibody & $\begin{array}{l}\text { Mouse monoclonal } \\
\text { anti-rab11a }\end{array}$ & Santa Cruz & $\begin{array}{l}\text { Cat\# sc-166523, } \\
\text { RRID:AB_2173466 }\end{array}$ & IF $(1: 20)$ \\
\hline Antibody & $\begin{array}{l}\text { Mouse monoclonal } \\
\text { anti- Golgin- } 97\end{array}$ & Invitrogen & $\begin{array}{l}\text { Cat\# A-21270, } \\
\text { RRID:AB_221447 }\end{array}$ & $\begin{array}{l}\text { IF }(1: 100) \\
\text { WB }(1: 1000)\end{array}$ \\
\hline Antibody & $\begin{array}{l}\text { Rat monoclonal } \\
\text { anti-Lamp1 }\end{array}$ & Santa Cruz & $\begin{array}{l}\text { Cat\# sc-19992, } \\
\text { RRID:AB_2134495 }\end{array}$ & $\begin{array}{l}\text { IF }(1: 20) \\
\text { WB }(1: 200)\end{array}$ \\
\hline Antibody & $\begin{array}{l}\text { Chicken } \\
\text { polyclonal anti-GFP }\end{array}$ & Abcam & $\begin{array}{l}\text { Cat\# ab13970, } \\
\text { RRID:AB_300798 }\end{array}$ & IF $(1: 200)$ \\
\hline Antibody & $\begin{array}{l}\text { Guinea pig Polyclonal } \\
\text { antiserum anti-Ankyrin G }\end{array}$ & Synaptic Systems & $\begin{array}{l}\text { Cat\# } 386004 \\
\text { RRID:AB_2725774 }\end{array}$ & IF $(1: 100)$ \\
\hline Antibody & $\begin{array}{l}\text { Rabbit } \\
\text { Polyclonal Anti-V5 }\end{array}$ & Millipore & $\begin{array}{l}\text { Cat\# AB3792 } \\
\text { RRID:AB_91591 }\end{array}$ & $\begin{array}{l}\text { IP }(1: 20) \\
\text { WB }(1: 1000)\end{array}$ \\
\hline Antibody & $\begin{array}{l}\text { Rat Monoclonal } \\
\text { Anti-DYKDDDDK Epitope Tag }\end{array}$ & Novus & $\begin{array}{l}\text { Cat\# NBP1-06712 } \\
\text { RRID:AB_1625981 }\end{array}$ & $\begin{array}{l}\text { IP }(1: 20) \\
\text { WB }(1: 1000)\end{array}$ \\
\hline Antibody & $\begin{array}{l}\text { Mouse Monoclonal } \\
\text { Anti-c-Myc }\end{array}$ & Sigma-Aldrich & $\begin{array}{l}\text { Cat\# M4439 } \\
\text { RRID:AB_439694 }\end{array}$ & $\begin{array}{l}\text { IP }(1: 20) \\
\text { WB }(1: 1000)\end{array}$ \\
\hline Antibody & $\begin{array}{l}\text { Goat anti-Chicken } \\
\lg (\mathrm{H}+\mathrm{L}) \text {, Alexa Fluor488 }\end{array}$ & Invitrogen & $\begin{array}{l}\text { Cat\# A-11039, } \\
\text { RRID:AB_142924 }\end{array}$ & IF $(1: 500)$ \\
\hline Antibody & $\begin{array}{l}\text { Goat anti-Rabbit IgG } \\
(\mathrm{H}+\mathrm{L}) \text {, Alexa Fluor488 }\end{array}$ & Invitrogen & $\begin{array}{l}\text { Cat\# A-11008, } \\
\text { RRID:AB_143165 }\end{array}$ & IF $(1: 500)$ \\
\hline Antibody & $\begin{array}{l}\text { Goat anti-Rat IgG }(\mathrm{H}+\mathrm{L}) \text {, } \\
\text { Alexa Fluor488 }\end{array}$ & Invitrogen & $\begin{array}{l}\text { Cat\# A-11006, } \\
\text { RRID:AB_141373 }\end{array}$ & IF $(1: 500)$ \\
\hline Antibody & $\begin{array}{l}\text { Goat anti- Mouse IgG } \\
(\mathrm{H}+\mathrm{L}) \text {, Alexa Fluor488 }\end{array}$ & Invitrogen & $\begin{array}{l}\text { Cat\# A-11029, } \\
\text { RRID:AB_138404 }\end{array}$ & IF $(1: 500)$ \\
\hline Antibody & $\begin{array}{l}\text { Goat anti-Rabbit lgG } \\
(\mathrm{H}+\mathrm{L}) \text {, Alexa Fluor555 }\end{array}$ & Invitrogen & $\begin{array}{l}\text { Cat\# A-11034, } \\
\text { RRID:AB_2576217 }\end{array}$ & IF $(1: 500)$ \\
\hline Antibody & $\begin{array}{l}\text { Goat anti-Guinea Pig lgG } \\
(\mathrm{H}+\mathrm{L}) \text {, Alexa Fluor555 }\end{array}$ & Invitrogen & $\begin{array}{l}\text { Cat\# A-21435, } \\
\text { RRID:AB_2535856 }\end{array}$ & IF $(1: 500)$ \\
\hline Antibody & $\begin{array}{l}\text { Peroxidase AffiniPure Donkey } \\
\text { Anti-Mouse IgG }(\mathrm{H}+\mathrm{L})\end{array}$ & $\begin{array}{l}\text { Jackson Immuno } \\
\text { Research Labs }\end{array}$ & $\begin{array}{l}\text { Cat\# 715-035-150, } \\
\text { RRID:AB_2340770 }\end{array}$ & WB (1:4000) \\
\hline Antibody & $\begin{array}{l}\text { Peroxidase AffiniPure Donkey } \\
\text { Anti-Rabbit IgG }(\mathrm{H}+\mathrm{L})\end{array}$ & $\begin{array}{l}\text { Jackson Immuno } \\
\text { Research Labs }\end{array}$ & $\begin{array}{l}\text { Cat\# 711-035-152, } \\
\text { RRID:AB_10015282 }\end{array}$ & WB (1:4000) \\
\hline Antibody & $\begin{array}{l}\text { Peroxidase AffiniPure Donkey } \\
\text { Anti-Rat lgG }(\mathrm{H}+\mathrm{L})\end{array}$ & $\begin{array}{l}\text { Jackson Immuno } \\
\text { Research Labs }\end{array}$ & $\begin{array}{l}\text { Cat\# 712-035-153, } \\
\text { RRID:AB_2340639 }\end{array}$ & WB (1:4000) \\
\hline $\begin{array}{l}\text { Chemical } \\
\text { compound, drug }\end{array}$ & Triton X-100 & Sigma & Cat\#X100 & In PBS $0.1 \%$ \\
\hline $\begin{array}{l}\text { Chemical } \\
\text { compound, drug }\end{array}$ & Trizol Reagent & Invitrogen & Cat\#15596026 & \\
\hline $\begin{array}{l}\text { Chemical } \\
\text { compound, drug }\end{array}$ & L15 medium & Gibco & 11415064 & $\begin{array}{l}\text { Medium for embryo } \\
\text { brain isolation on ice }\end{array}$ \\
\hline $\begin{array}{l}\text { Chemical } \\
\text { compound, drug }\end{array}$ & Mounting Medium & Vector Laboratories & Cat\#H-1000 & \\
\hline $\begin{array}{l}\text { Chemical } \\
\text { compound, drug }\end{array}$ & $0.05 \%$ trypsin/EDTA & Gibco & $25300-054$ & \\
\hline $\begin{array}{l}\text { Chemical } \\
\text { compound, drug }\end{array}$ & SVF & Invitrogen & 10270106 & \\
\hline $\begin{array}{l}\text { Chemical } \\
\text { compound, drug }\end{array}$ & DNAse & Serlabo & LS002138 & \\
\hline $\begin{array}{l}\text { Chemical } \\
\text { compound, drug }\end{array}$ & Neurobasal medium & Gibco & 21103049 & \\
\hline $\begin{array}{l}\text { Chemical } \\
\text { compound, drug }\end{array}$ & B27 supplement & Gibco & $17504-044$ & \\
\hline
\end{tabular}

Continued on next page 
Continued

\begin{tabular}{|c|c|c|c|c|}
\hline $\begin{array}{l}\text { Reagent type (species) } \\
\text { or resource }\end{array}$ & Designation & Source or reference & Identifiers & Additional information \\
\hline $\begin{array}{l}\text { Chemical } \\
\text { compound, drug }\end{array}$ & L-glutamax & Gibco & $35050-061$ & \\
\hline $\begin{array}{l}\text { Chemical } \\
\text { compound, drug }\end{array}$ & Wnt3a & R and D Systems & 645-WN-010 & \\
\hline $\begin{array}{l}\text { Chemical } \\
\text { compound, drug }\end{array}$ & Wnt5a & $R$ and D Systems & 1324-WNP-010 & \\
\hline $\begin{array}{l}\text { Chemical } \\
\text { compound, drug }\end{array}$ & Bafilomycin A1 & invitrogen & $88899-55-2$ & \\
\hline $\begin{array}{l}\text { Chemical } \\
\text { compound, drug }\end{array}$ & LY294002 & Sigma & L9908 & \\
\hline $\begin{array}{l}\text { Chemical } \\
\text { compound, drug }\end{array}$ & Lipofectamine 3000 & Thermofisher & Cat\#L3000008 & \\
\hline $\begin{array}{l}\text { Chemical } \\
\text { compound, drug }\end{array}$ & DMEM & Gibco & Cat\#10566016 & \\
\hline $\begin{array}{l}\text { Chemical } \\
\text { compound, drug }\end{array}$ & Penicillin-Streptomycin & Gibco & Cat\#15140122 & \\
\hline $\begin{array}{l}\text { Biological sample } \\
\text { (M. musculus) }\end{array}$ & APP-KO mouse & $\begin{array}{l}\text { A gift from Bart } \\
\text { De Strooper's lab }\end{array}$ & N/A & \\
\hline $\begin{array}{l}\text { Cell line } \\
\text { (Homo-sapiens) }\end{array}$ & Hek293 & $\begin{array}{l}\text { A gift from } \\
\text { Marie-Claude Potier's lab }\end{array}$ & N/A & \\
\hline $\begin{array}{l}\text { Sequence-based } \\
\text { reagent }\end{array}$ & mAPP_F & $\begin{array}{l}\text { This paper } \\
\text { Ordered from IDT }\end{array}$ & PCR primers & CATCCAGAACTGGTGCAAGCG \\
\hline $\begin{array}{l}\text { Sequence-based } \\
\text { reagent }\end{array}$ & mAPP_R & $\begin{array}{l}\text { This paper } \\
\text { Ordered from IDT }\end{array}$ & PCR primers & GACGGTGTGCCAGTGAAGATG \\
\hline $\begin{array}{l}\text { Sequence-based } \\
\text { reagent }\end{array}$ & $\beta$-actin_F & $\begin{array}{l}\text { This paper } \\
\text { Ordered from IDT er }\end{array}$ & PCR primers & TCCATCATGAAGTGTGACGT \\
\hline $\begin{array}{l}\text { Sequence-based } \\
\text { reagent }\end{array}$ & $\beta$-actin_R & $\begin{array}{l}\text { This paper } \\
\text { Ordered from IDT } r\end{array}$ & PCR primers & GAGCAATGATCTTGATCTTCAT \\
\hline $\begin{array}{l}\text { Transfected } \\
\text { construct (M. musculus) }\end{array}$ & $\begin{array}{l}\text { pLv-pSyn1- } \\
\text { mAPP-Flag-IRESeGFP }\end{array}$ & $\begin{array}{l}\text { ICM-institute, } \\
\text { Virus facility }\end{array}$ & $\mathrm{N} / \mathrm{A}$ & $\begin{array}{l}\text { Lentiviral construct to } \\
\text { transfect and express the mAPP }\end{array}$ \\
\hline $\begin{array}{l}\text { Transfected } \\
\text { construct (M. musculus) }\end{array}$ & $\begin{array}{l}\text { pLv-pSyn1- } \\
\text { mAPP } \Delta \text { CRD-Flag-IRESeGFP }\end{array}$ & $\begin{array}{l}\text { ICM-institute, } \\
\text { Virus facility }\end{array}$ & N/A & $\begin{array}{l}\text { Lentiviral construct to } \\
\text { transfect and express the } \\
\text { mAPP- } \Delta \text { CRD }\end{array}$ \\
\hline $\begin{array}{l}\text { Transfected } \\
\text { construct (M. musculus) }\end{array}$ & pLv-pSyn1- eGFP & $\begin{array}{l}\text { ICM-institute, } \\
\text { Virus facility }\end{array}$ & $\mathrm{N} / \mathrm{A}$ & $\begin{array}{l}\text { Lentiviral construct to } \\
\text { transfect and express the GFP }\end{array}$ \\
\hline $\begin{array}{l}\text { Transfected } \\
\text { construct (M. musculus) }\end{array}$ & $\begin{array}{l}\text { pCDNA3- } \\
\text { mApp-FLAG-IRES-eGFP }\end{array}$ & This paper & $N / A$ & transfected construct \\
\hline $\begin{array}{l}\text { Transfected } \\
\text { construct (M. musculus) }\end{array}$ & $\begin{array}{l}\text { PCDNA3-mAPPACRD- } \\
\text { FLAG-IRES-eGFP }\end{array}$ & This paper & $N / A$ & transfected construct \\
\hline $\begin{array}{l}\text { Transfected } \\
\text { construct (M. musculus) }\end{array}$ & pCDNA3-Wnt5a-myc & This paper & $N / A$ & transfected construct \\
\hline $\begin{array}{l}\text { Transfected } \\
\text { construct (M. musculus) }\end{array}$ & pCDNA-Wnt3A-V5 & This paper & $\mathrm{N} / \mathrm{A}$ & transfected construct \\
\hline $\begin{array}{l}\text { Transfected } \\
\text { construct (human) }\end{array}$ & $\begin{array}{l}\text { pCDNA3-hApp- } \\
\text { FLAG-IRES-eGFP }\end{array}$ & This paper & N/A & transfected construct \\
\hline $\begin{array}{l}\text { Transfected } \\
\text { construct (human) }\end{array}$ & $\begin{array}{l}\text { pCDNA3-hAPP } \triangle \text { CRD- } \\
\text { FLAG-IRES-eGFP }\end{array}$ & This paper & $N / A$ & transfected construct \\
\hline $\begin{array}{l}\text { Commercial } \\
\text { assay or kit }\end{array}$ & $\begin{array}{l}\text { QuantiTect Reverse } \\
\text { Transcription Kit }\end{array}$ & Qiagen & Cat\# 205311 & \\
\hline $\begin{array}{l}\text { Commercial } \\
\text { assay or kit }\end{array}$ & $\begin{array}{l}\text { LightCycler480 SYBR } \\
\text { Green I Master }\end{array}$ & Roche & Cat\# 04707516001 & \\
\hline $\begin{array}{l}\text { Commercial } \\
\text { assay or kit }\end{array}$ & $\begin{array}{l}4-12 \% \text { polyacrylamide gels } \\
\text { (SDS-PAGE) }\end{array}$ & ThermoFisher & NW04122BOX & \\
\hline
\end{tabular}

Continued on next page 
Continued

\begin{tabular}{|c|c|c|c|c|}
\hline $\begin{array}{l}\text { Reagent type (species) } \\
\text { or resource }\end{array}$ & Designation & Source or reference & Identifiers & Additional information \\
\hline $\begin{array}{l}\text { Commercial } \\
\text { assay or kit }\end{array}$ & $\begin{array}{l}\text { Protein } \mathrm{G} \\
\text { sepharose beads }\end{array}$ & ThermoFisher & $\begin{array}{l}\text { Ref.10612D } \\
\text { Lot.00644644 }\end{array}$ & \\
\hline Other & Nikon & $A 1-R$ & & \\
\hline Other & Olympus & FV-1200 & & \\
\hline Other & DAPI & Sigma & Cat\# D9564 & $1 \mathrm{ug} / \mathrm{ml}$ \\
\hline Software, algorithm & $\begin{array}{l}\text { GraphPad } \\
\text { Prism software }\end{array}$ & $\begin{array}{l}\text { GraphPad Prism } \\
\text { (https://graphpad.com) }\end{array}$ & RRID:SCR_015807 & \\
\hline Software, algorithm & ImageJ software & $\begin{array}{l}\text { ImageJ } \\
\text { (http://imagej.nih.gov/ij/) }\end{array}$ & RRID:SCR_003070 & \\
\hline
\end{tabular}

\section{Drosophila stocks and maintenance}

Flies were raised at $25^{\circ} \mathrm{C}$, on standard cornmeal and molasses medium. The stocks used in this study are: $\mathrm{w}^{\star}, \mathrm{Appl}^{\mathrm{d}}$; Vang ${ }^{\mathrm{stbm}-6} ; \mathrm{w} 1118, \mathrm{Wnt}^{400} ; \mathrm{P} 247 \mathrm{Gal} 4 ; \mathrm{w}^{*}, \mathrm{Appl}^{\mathrm{d}}, \mathrm{Wnt5}^{400}$.

\section{Cloning}

All constructs were generated by PCR amplification and overlap extension PCR. PCR products were inserted into the respective vectors by classical restriction enzyme cloning. All constructs were sequence-verified. To generate transgenic flies, open-reading frames with epitope tags were cloned into the pUAST-attB fly expression vector and transgenes were inserted into the genome at the VK37 docking site (2L, 22A3) via PhiC31-mediated transgenesis.

\section{Mushroom body analyses}

Adult fly brains were dissected in phosphate buffered saline (PBS) and fixed in $3.7 \%$ formaldehyde in PBT (PBS+ 0.1\% Triton 100-X) for 15 min. Then, the brains were washed three times in PBT and blocked in PAX-DG for $1 \mathrm{hr}$ at RT. The samples were later incubated with the primary antibody overnight at $4^{\circ} \mathrm{C}$. After incubation, the brains were washed three times with PBT and incubated with an ALEXA Fluor secondary antibodies (Life technologies) for $2 \mathrm{hr}$ at RT. After three times washes in PBT, the brains were mounted in Vectashield (Vector Labs, USA) mounting medium. The following antibodies were used: mouse anti-Fasll (Developmental Studies Hybridoma Bank (DSHB), 1/50), rabbit anti-GFP (Invitrogen, 1/500). The mounted brains were imaged on a LEICA DM 6000 CS microscope coupled to a LEICA CTR 6500 confocal system and a Nikon A1-R confocal (Nikon) mounted on a Nikon inverted microscope (Nikon). The pictures were then processed using ImageJ.

\section{Primary cortical neuron culture, virus transduction, and plasmids transfection}

All experiments were done according to policies on the care and use of laboratory animals of European Communities Council Directive (2010/63). The protocols were approved by the French Research Ministry following evaluation by a specialized ethics committee (dossier number 4437). APP knock out mice were a gift from the De Strooper lab. Cortical primary neuron cultures were prepared from embryonic day 16.5 mice (APP wild or APP mutant), as described previously (Cheng et al., 2016).

Virus (pLv-pSyn1-mAPP-Flag-IRESeGFP, pLv-pSyn1-mAPP $\triangle$ CRD-Flag-IRESeGFP, or pLv-pSyn1eGFP) transduction was performed during seeding in 24 -well plates $\left(4 \times 10^{5}\right.$ cells $\left./ \mathrm{mL}\right)$. Fifty $\mu \mathrm{L}(50 \mu \mathrm{L}$ par well) of the adequate lentiviral dilution in the medium of interest must be ready in tubes. Seed $150 \mu \mathrm{L}$ of the cell preparation to each well. Immediately add $50 \mu$ l of the diluted lentiviral preparation to each well (final MOI 2). Mix slowly the cells-lentivirus suspension by pipetting. Incubate $1 \mathrm{hr}$ at $37^{\circ} \mathrm{C}$. Finally add $800 \mu \mathrm{L}$ of culture medium to each well and incubate for 3 additional days before any analysis.

Plasmids (pLv794_pTrip_PromSynaptin1_GFP_DeltaU3, pLv-pSyn1-MmApp-FLAG-IRES-eGFP, or pLv-pSyn1-mAPP $\triangle$ CRD-FLAG-IRES-eGFP) transfection was performed at the onset of cell seeding $\left(4 \times 10^{5}\right.$ cells $\left./ \mathrm{mL}\right)$ in 24 wells plates with coverslip coated with PDL $24 \mathrm{hr}$ before. All procedure follow 
the protocol from Lipofectamine 3000 transfection reagent (Thermofisher Catalog Number: L3000008) with little modified, each well transfection with 500 ng corresponding plasmid, medium was refreshed 5-6 hr after transfection.

\section{Wnt and inhibitor treatment in primary neuron}

Wnt5a (400 ng/ml) (645-WN-010, R and D Systems), Wnt3a (150 ng/ml) (1324-WNP-010, R and D Systems), and PBS/BSA (control) addition performed at DIV7. In all experiments related to inhibitor, cells will be treated with inhibitor $1 \mathrm{hr}$ after Wnt addition (Bafilomycin A1, $100 \mathrm{nM}$, Invitrogen, 88899-55-2), LY294002 (10 $\mu \mathrm{M}$, Sigma, L9908) and a DMSO (0.05\%DMSO in culture medium) group will be set as control. Protein or RNA samples collected after $4 \mathrm{hr}$ of Wht treatment.

\section{A $\mathbf{\beta}$ 40/42 detection}

For the $A \beta 40 / 42$ detection, first, culture medium refreshed with Wnt3a $(50 \mathrm{ng} / \mathrm{ml}$ or $150 \mathrm{ng} / \mathrm{ml}$ ) or Wnt5a (100 ng/ml or $400 \mathrm{ng} / \mathrm{ml}$ ) on DIV7 primary cortical neurons. Then, supernatant was collected after $4 \mathrm{hr}$ Wnt3a/5a treatment for $A \beta$ detection, and refreshed with medium without Wnt3a/5a. At last, the second round supernatant collection performed after additional $24 \mathrm{hr}$ culture. The procedure of $A \beta$ detection is based on the protocol from V-PLEX Plus $A \beta$ Peptide Panel 1 (6E10) Kit (K15200G, MSD).

\section{Amino acids sequence of deleted CRD}

Amino acids with underscore are deleted in mouse, human APP $\triangle$ CRD or APPL $\triangle C R D$.

hAPP695 (NCBI Reference Sequence: NP_958817.1)

MLPGLALLLLAAWTARALEVPTDGNAGLLAEPQIAMFCGRLNMHMNVQNGKWDSDPSGTKTC IDTKEGILQYCQEVYPELQITNVVEANQPVTIQNWCKRGRKQCKTHPHFVIPYRCLVGEFVSDAL LVPDKCKFLHQERMDVCETHLHWHTVAKETCSEKSTNLHDYGMLLPCGIDKFRGVEFVCCPLA EESDNVDSADAEEDDSDVWWGGADTDYADGSEDKVVEVAEEEEVAEVEEEEADDDEDDEDGD EVEEEAEEPYEEATERTTSIATTTTTTTESVEEVVRVPTTAASTPDAVDKYLETPGDENEHAHFQ KAKERLEAKHRERMSOVMREWEEAERQAKNLPKADKKAVIQHFQEKVESLEQEAANERQQL VETHMARVEAMLNDRRRLALENYITALQAVPPRPRHVFNMLKKYVRAEQKDRQHTLKHFEHV RMVDPKKAAQIRSOVMTHLRVIYERMNQSLSLLYNVPAVAEEIODEVDELLQKEQNYSDDVLAN MISEPRISYGNDALMPSLTETKTTVELLPVNGEFSLDDLQPWHSFGADSVPANTENEVEPVDAR PAADRGLTTRPGSGLTNIKTEEISEVKMDAEFRHDSGYEVHHOKLVFFAEDVGSNKGAIIGLMVG GVVIATVIVITLVMLKKKOYTSIHHGVVEVDAAVTPEERHLSKMQQNGYENPTYKFFEQMQN.

MmApp (NCBI Reference Sequence: NP_031497.2) MLPSLALLLLAAWTVRALEVPTDGNAGLLAEPOIAMFCGKLNMHMNVONGKWESDPSGTKTC IGTKEGILOYCOEVYPELOITNVVEANOPVTIONWCKRGRKOCKTHTHIVIPYRCLVGEFVSDALL VPDKCKFLHOERMDVCETHLHWHTVAKETCSEKSTNLHDYGMLLPCGIDKFRGVEFVCCPLAE ESDSVDSADAEEDDSDVWWGGADTDYADGGEDKVVEVAEEEEVADVEEEEADDDEDVEDGDEV EEEAEEPYEEATERTTSTATTTTTTTTESVEEVVRVPTTAASTPDAVDKYLETPGDENEHAHFOKAK ERLEAKHRERMSOVMREWEEAERQAKNLPKADKKAVIQHFOEKVESLEQEAANEROQLVETHM ARVEAMLNDRRRLALENYITALOAVPPRPHHVFNMLKKYVRAEOKDROHTLKHFEHVRMVDPKK AAOIRSOVMTHLRVIYERMNOSLSLLYNVPAVAEEIODEVDELLOKEONYSDDVLANMISEPRISYG NDALMPSLTETKTTVELLPVNGEFSLDDLOPWHPFGVDSVPANTENEVEPVDARPAADRGLTT RPGSGLTNIKTEEISEVKMDAEFGHDSGFEVRHOKLVFFAEDVGSNKGAIIGLMVGGVVIATVIVITL VMLKKKOYTSIHHGVVEVDAAVTPEERHLSKMQONGYENPTYKFFEOMON.

appl (Drosophila melanogaster) (NCBI Reference Sequence:

NP_001245451.1)

mcaalrrnlllrslwvvlaigtaqvqaasprwepqiavlceagqiyqpqylseegrwvtdlskkttgptclrdkmdlldyc kkaypnrditnivesshyqkiggwcragalnaakckgshrwikpfrclgpfasdallvpegclfdhihnasrcwpfvrwn qtgaaacqergmamrsfamllpcgisvfsgvefvccpkhfktdeihvkktdlpvmpaaqinsandelvmndeddsn dsnyskdaneddlddeddlmgddeeddmvadeaataggspntgssgdsnsgslddinaeydsgeegdnyeedg agseseaeveaswdqsggakvvslksdssspssapvapapekapvksesvtstpqlsasaaafvaansgnsgtgaga 
ppstaqptsdpyfthfdphyehqsykrleeshrekvtrvmkdwsdleekyqdmrladpkaaqsfkqrmtarfqtsv qaleeegnaekhqlaamhqqrvlahinqrkreamtcytqalteqppnahhvekclqkllralhkdrahalahyrhlln sggpggleaaaserprtlerlididravnqsmtmlkrypelsakiaqlmndyilalrskddipgsslgmseeaeagildk yrveierkvaekerlrlaekqrkeqraaereklreeklrleakkvddmlksqvaeqqsqptqsstqsqaqqqqqekslp gkelgpdaalvtaanpnlettksekdlsdteygeatvsstkvqtvlptvdddavqravedvaaavahqeaepqvqhf mthdlghressfs/rrefaqhahaakegrnvyftlsfagialmaavfvgvavakwrtsrsphaqgfievdqnvtthhpiv reekivpnmqingyenptykyfevke.

\section{Quantitative real-time PCR (qRT-PCR)}

Cells were lysed for RNA or protein extraction and then subjected to qRT-PCR or western blots as previously described (Liu et al., 2014). The detailed sequence of each primer used in the whole study for qRT-PCR were summarized below : $\beta$-actin, sense $5^{\prime}$ - TCCATCATGAAGTGTGACGT-3' and anti-sense 5'- GAGCAATGATCTTGATCTTCAT -3', mAPP, sense 5'- CATCCAGAACTGG TGCAAGCG-3' and anti-sense 5'- GACGGTGTGCCAGTGAAGATG -3' GAPDH, sense 5'- GC TGCCAAGGCTGTGGGCAAG-3' and anti-sense 5'- GCCTGCTTCACCACCTTC -3'.

\section{Western blots}

Western blots were performed follow the user guide of Mini Gel Tank (ThermoFisher, A25977) with little modified. Briefly, Protein samples collected from total cell lysates with RIPA buffer, supernatant were collected after centrifugation, denatured samples were loaded separated on the 4-12\% polyacrylamide gels (SDS-PAGE) (ThermoFisher, NW04122BOX) and then transferred to the $0.42 \mu \mathrm{m}$ nitrocellulose membranes, blots visualization performed after primary and secondary antibody incubation.

\section{Immunoprecipitation}

Human embryonic kidney (HEK293) cells (provided from Dr. Marie-Claude Potier) were purchased from ATCC, regularly mycoplasma test performed by the CELIS core facility of ICM. For the immunoprecipitation experiments, HEK293in $10 \mathrm{~cm}$ dish (70\% confluent) were transfected with pCDNA3MmApp-FLAG-IRES-eGFP, pCDNA3-mAPPACRD-FLAG-IRES-eGFP, pCDNA3-Wnt5a-myc, pCDNAWnt3A-V5 or co-transfected APP or APP $\triangle$ CRD with Wnt3a or Wnt5a. Three days after transfection, cells were collected with NP-40 lysis buffer, then sample supernatant was collected after $>12000$ rpm centrifugation for $20 \mathrm{~min}$ at $4^{\circ} \mathrm{C}, 450 \mu$ l supernatant was incubated with primary antibody overnight at $4^{\circ} \mathrm{C}$, then Protein $\mathrm{G}$ sepharose beads (Thermo Fisher Scientific) were added to the sample to capture protein-antibody complex by rotating $2 \mathrm{hr}$ at room temperature, then washed four times with the lysis buffer, and resuspended with loading buffer then denatured at 95 degree for 10 min, blots visualized after western blot procedure as described before.

\section{Immunofluorescence}

At DIV 7, cultured primary neurons in 24 wells were washed once with 1 X PBS, then fixed in $4 \%$ paraformaldehyde (PFA) in PBS at room temperature (RT) for $10 \mathrm{~min}$. After three times washing with $1 \mathrm{X}$ PBS, cells were blocked with $10 \%$ normal donkey or goat serum in 1 X PBS for 30 min at RT followed by three times washing in 1 X PBS. Thereafter, cells were incubated with primary antibodies diluted in 1 X PBS containing $1 \%$ normal donkey or goat serum for 2-3 hr at RT. three times washing with 1 $X$ PBS, incubated with appropriate secondary antibodies conjugated with Alexa Fluor 488, Alexa Fluor 555, or Alexa Fluor 647 (1:500, Invitrogen) in 1 X PBS containing $1 \%$ normal donkey or goat serum for $1 \mathrm{hr}$ at RT. Washed with 1 X PBS for three times, then counterstained the slides with DAPI (1:2000, Sigma) and mounted by using Vectashield (Vector) after rinsing. Primary antibodies used in this study were rabbit anti-APP (1:100, Synaptic Systems, 127 003), mouse anti-rab5 (1:100, Synaptic Systems, 108011), mouse anti-rab11a (1:20, Santa Cruz, sc-166523), mouse anti- Golgin-97 (1:100, Invitrogen, A-21270), rat anti-Lamp1 (1:20, Santa Cruz, sc-19992). After staining, images were obtained by using confocal microscope (Olympus FV-1200 or Leica SP8). The percentage of APP or APP- $\triangle$ CRD co-localizing with rab5, rab11, Golgin-97 and Lamp1 was calculated using JACOP (Bolte and Cordelières, 2006). 


\section{Statistical analyses}

Statistical analyses were performed using GraphPad Prism software (GraphPad Software Inc, La Jolla, CA, USA). Differences between groups were compared using the Student's $t$ test, One-way ANOVA and Mann Whitney two-sample test (two-tail) as appropriate.

\section{Acknowledgements}

We thank Dr. Radoslaw Ejsmont for writing the co-localization macro, Natalia Danda for the construction of the plasmids used in this work, Drs. Ariane Ramaekers, Natalia Mora Garcia, Gerit Linneweber, Simon Weinberger and Guangda Liu for helpful discussions. We thank Drs. Zeynep Kalender Atak and Marina Naval Sanchez for support on the statistical analysis of the data and Dr. Jean-Maurice Dura for fly lines. Mouse breeding work was conducted at the PHENO-ICMice facility. The Core is supported by 2 Investissements d'Avenir grants (ANR-10- IAIHU-06 and ANR-11-INBS-0011-NeurATRIS) and the 'Fondation pour la Recherche Médicale'. Primary neuron culture work was carried out at the CELIS core facility with support from Program Investissements d'Avenir (ANR-10-IAIHU06). Light microscopy was carried out at the ICM.Quant facility. We thank all core technical staff involved. We thank Philippe Ravassard for providing the pSYN lentiviral vector backbone and Blandine Bonnamy and Clementine Ripoll from iVECTOR core facolity for technical assistance and production of the lentiviral vectors. This work was supported by Fonds Wetenschappelijke Onderzoeks (FWO) grants G.0543.08, G.0680.10, G.0681.10 and G.0503.12, the program 'Investissements d'avenir' ANR-10-IAIHU-06, the Einstein-BIH program, the Neuro-Glia Foundation, a Sorbonne Université Emergence grant, an Allen Distinguished Investigator Award and the Roger De Spoelberch Foundation Prize (to BAH), ANR-12-MALZ-0004 grant (to MCP), the Vlaams Instituut voor Biotechnologie and the Methusalem grants from KU Leuven (to BDS and BAH), the Nederlandse Organisatie voor Wetenschappelijk Onderzoek (NWO; ZonMw TOP grant 40-00812-98-10058) and the Hersenstichting Nederland [HS 2011(1)-46] (to LGF), a doctoral fellowship from the Centre National de Recherche Scientifique Libanais (to MN) and Chinese Scholarship Council fellowships (to TZ and TL). The authors declare no competing financial interests.

\section{Additional information}

Funding

\begin{tabular}{|c|c|c|}
\hline Funder & Grant reference number & Author \\
\hline China Scholarship Council & & Tengyuan Liu \\
\hline Hersenstichting & HS 2011(1)-46 & Lee Fradkin \\
\hline $\begin{array}{l}\text { Lebanese National Council for } \\
\text { Scientific Research }\end{array}$ & & Maya Nicolas \\
\hline $\begin{array}{l}\text { Vlaams Instituut voor Biotech- } \\
\text { nologie }\end{array}$ & & $\begin{array}{l}\text { Bart De Strooper } \\
\text { Bassem A Hassan }\end{array}$ \\
\hline $\begin{array}{l}\text { Fondation Roger de Spoel- } \\
\text { berch }\end{array}$ & $1911001 \mathrm{IN}$ & Bassem A Hassan \\
\hline $\begin{array}{l}\text { Agence Nationale de la Re- } \\
\text { cherche }\end{array}$ & ANR-10-IAIHU-06 & $\begin{array}{l}\text { Marie-Claude Potier } \\
\text { Bassem A Hassan }\end{array}$ \\
\hline $\begin{array}{l}\text { Fonds Wetenschappelijk On- } \\
\text { derzoek }\end{array}$ & G.0543.08 & Bassem A Hassan \\
\hline Neuron-Glia Foundation & 2003009NA & Bassem A Hassan \\
\hline KU Leuven & Methusalem & $\begin{array}{l}\text { Bart De Strooper } \\
\text { Bassem A Hassan }\end{array}$ \\
\hline $\begin{array}{l}\text { Nederlandse Organisatie voor } \\
\text { Wetenschappelijk Onderzoek }\end{array}$ & 40-00812-98-10058 & Lee Fradkin \\
\hline $\begin{array}{l}\text { Fonds Wetenschappelijk On- } \\
\text { derzoek }\end{array}$ & G.0680.10 & Bassem A Hassan \\
\hline Fonds Wetenschappelijk On- & G.0681.10 & Bassem A Hassan \\
\hline
\end{tabular}




\begin{tabular}{lll}
$\begin{array}{l}\text { derzoek } \\
\begin{array}{l}\text { Fonds Wetenschappelijk On- } \\
\text { derzoek }\end{array}\end{array}$ & G.0503.12 & Bassem A Hassan \\
\hline $\begin{array}{l}\text { Agence Nationale de la Re- } \\
\text { cherche }\end{array}$ & $\begin{array}{l}\text { ANR-11-INBS-0011- } \\
\text { NeurATRIS }\end{array}$ & $\begin{array}{l}\text { Marie-Claude Potier } \\
\text { Bassem A Hassan }\end{array}$ \\
\hline $\begin{array}{l}\text { Agence Nationale de la Re- } \\
\text { cherche }\end{array}$ & ANR-12-MALZ-0004 & $\begin{array}{l}\text { Marie-Claude Potier } \\
\text { Bassem A Hassan }\end{array}$ \\
\hline
\end{tabular}

The funders had no role in study design, data collection and interpretation, or the decision to submit the work for publication.

Author contributions

Tengyuan Liu, Conceptualization, Formal analysis, Investigation, Methodology, Writing - original draft, Writing - review and editing; Tingting Zhang, Formal analysis, Investigation, Methodology; Maya Nicolas, Conceptualization, Formal analysis, Investigation, Methodology, Writing - original draft; Lydie Boussicault, Heather Rice, Investigation, Methodology; Alessia Soldano, Conceptualization, Investigation; Annelies Claeys, Iveta Petrova, Investigation; Lee Fradkin, Conceptualization, Supervision, Funding acquisition; Bart De Strooper, Marie-Claude Potier, Supervision, Funding acquisition; Bassem A Hassan, Conceptualization, Supervision, Funding acquisition, Writing - original draft, Project administration, Writing - review and editing

Author ORCIDs

Maya Nicolas (DiD https://orcid.org/0000-0002-7148-6357

Alessia Soldano (iD http://orcid.org/0000-0002-3120-9929

Bart De Strooper (iD http://orcid.org/0000-0001-5455-5819

Marie-Claude Potier (iD http://orcid.org/0000-0003-2462-7150

Bassem A Hassan (D) https://orcid.org/0000-0001-9533-4908

Ethics

Animal experimentation: All experiments were done according to policies on the care and use of laboratory animals of European Communities Council Directive (2010/63). The protocols were approved by the French Research Ministry following evaluation by a specialized ethics committee (dossier number 4437).

Decision letter and Author response

Decision letter https://doi.org/10.7554/eLife.69199.sa1

Author response https://doi.org/10.7554/eLife.69199.sa2

\section{Additional files}

Supplementary files

- Supplementary file 1. Genetic interaction between Wnt5 and Vang. The table lists the penetrance of the phenotype and the number of brains analyzed in the Vang-Wnt5 genetic interaction experiment.

- Transparent reporting form

Data availability

No new datasets were generated in this study.

\section{References}

Ables JL, Breunig JJ, Eisch AJ, Rakic P. 2011. Not(ch) just development: notch signalling in the adult brain. Nature Reviews Neuroscience 12:269-283. DOI: https://doi.org/10.1038/nrn3024, PMID: 21505516 
Araki W, Kitaguchi N, Tokushima Y, Ishii K, Aratake H, Shimohama S, Nakamura S, Kimura J. 1991. Trophic effect of beta-amyloid precursor protein on cerebral cortical neurons in culture. Biochemical and Biophysical Research Communications 181:265-271. DOI: https://doi.org/10.1016/S0006-291X(05)81412-3, PMID: 1958195

Barnes AP, Polleux F. 2009. Establishment of axon-dendrite polarity in developing neurons. Annual Review of Neuroscience 32:347-381. DOI: https://doi.org/10.1146/annurev.neuro.31.060407.125536, PMID: 19400726

Billnitzer AJ, Barskaya I, Yin C, Perez RG. 2013. APP independent and dependent effects on neurite outgrowth are modulated by the receptor associated protein (RAP). Journal of Neurochemistry 124:123-132. DOI: https:// doi.org/10.1111/jnc.12051, PMID: 23061396

Bolte S, Cordelières FP. 2006. A guided tour into subcellular colocalization analysis in light microscopy. Journal of Microscopy 224:213-232. DOI: https://doi.org/10.1111/j.1365-2818.2006.01706.x, PMID: 17210054

Bush Al, Multhaup G, Moir RD, Williamson TG, Small DH, Rumble B, Pollwein P, Beyreuther K, Masters CL. 1993. A novel zinc(II) binding site modulates the function of the beta A4 amyloid protein precursor of Alzheimer's disease. Journal of Biological Chemistry 268:16109-16112. DOI: https://doi.org/10.1016/S0021-9258(19)853942

Cassar M, Kretzschmar D. 2016. Analysis of amyloid precursor protein function in Drosophila melanogaster. Frontiers in Molecular Neuroscience 9:61. DOI: https://doi.org/10.3389/fnmol.2016.00061, PMID: 27507933

Chang KA, Kim HS, Ha TY, Ha JW, Shin KY, Jeong YH, Lee JP, Park CH, Kim S, Baik TK, Suh YH. 2006. Phosphorylation of amyloid precursor protein (APP) at Thr668 regulates the nuclear translocation of the APP intracellular domain and induces neurodegeneration. Molecular and Cellular Biology 26:4327-4338. DOI: https://doi.org/10.1128/MCB.02393-05, PMID: 16705182

Chen CD, Oh SY, Hinman JD, Abraham CR. 2006. Visualization of APP dimerization and APP-Notch2 heterodimerization in living cells using bimolecular fluorescence complementation. Journal of Neurochemistry 97:30-43. DOI: https://doi.org/10.1111/j.1471-4159.2006.03705.x, PMID: 16515557

Cheng A, Yang Y, Zhou Y, Maharana C, Lu D, Peng W, Liu Y, Wan R, Marosi K, Misiak M, Bohr VA, Mattson MP. 2016. Mitochondrial SIRT3 mediates adaptive responses of neurons to exercise and metabolic and excitatory challenges. Cell Metabolism 23:128-142. DOI: https://doi.org/10.1016/j.cmet.2015.10.013, PMID: 26698917

Coburger I, Dahms SO, Roeser D, Gührs KH, Hortschansky P, Than ME. 2013. Analysis of the overall structure of the multi-domain amyloid precursor protein (APP). PLOS ONE 8:e81926. DOI: https://doi.org/10.1371/journal. pone.0081926, PMID: 24324731

Coronel R, Bernabeu-Zornoza A, Palmer C, Muñiz-Moreno M, Zambrano A, Cano E, Liste I. 2018. Role of amyloid precursor protein (APP) and its derivatives in the biology and cell fate specification of neural stem cells. Molecular Neurobiology 55:7107-7117. DOI: https://doi.org/10.1007/s12035-018-0914-2, PMID: 29383688

Dann CE, Hsieh JC, Rattner A, Sharma D, Nathans J, Leahy DJ. 2001. Insights into wnt binding and signalling from the structures of two frizzled cysteine-rich domains. Nature 412:86-90. DOI: https://doi.org/10.1038/ 35083601, PMID: 11452312

Deyts C, Thinakaran G, Parent AT. 2016. APP receptor? to be or not to be. Trends in Pharmacological Sciences 37:390-411. DOI: https://doi.org/10.1016/j.tips.2016.01.005, PMID: 26837733

Dotti CG, Sullivan CA, Banker GA. 1988. The establishment of polarity by hippocampal neurons in culture. The Journal of Neuroscience 8:1454-1468. DOI: https://doi.org/10.1523/JNEUROSCI.08-04-01454.1988, PMID: 32 82038

Eisenmann DM. 2005. Wnt signaling. WormBook 1:1-17. DOI: https://doi.org/10.1895/wormbook.1.7.1, PMID: 1 8050402

El Ayadi A, Stieren ES, Barral JM, Boehning D. 2012. Ubiquilin-1 regulates amyloid precursor protein maturation and degradation by stimulating K63-linked polyubiquitination of lysine 688. PNAS 109:13416-13421. DOI: https://doi.org/10.1073/pnas.1206786109, PMID: 22847417

Elliott C, Rojo Al, Ribe E, Broadstock M, Xia W, Morin P, Semenov M, Baillie G, Cuadrado A, Al-Shawi R, Ballard CG, Simons P, Killick R. 2018. A role for APP in wnt signalling links synapse loss with $\beta$-amyloid production. Translational Psychiatry 8:179. DOI: https://doi.org/10.1038/s41398-018-0231-6, PMID: 30232325

Grillenzoni N, Flandre A, Lasbleiz C, Dura JM. 2007. Respective roles of the DRL receptor and its ligand WNT5 in Drosophila mushroom body development. Development 134:3089-3097. DOI: https://doi.org/10.1242/dev. 02876, PMID: 17652353

Haass C, Kaether C, Thinakaran G, Sisodia S. 2012. Trafficking and proteolytic processing of APP. Cold Spring Harbor Perspectives in Medicine 2:a006270. DOI: https://doi.org/10.1101/cshperspect.a006270, PMID: 225534 93

Heisenberg M. 2003. Mushroom body memoir: from maps to models. Nature Reviews Neuroscience 4:266-275. DOI: https://doi.org/10.1038/nrn1074, PMID: 12671643

Hoe HS, Lee KJ, Carney RS, Lee J, Markova A, Lee JY, Howell BW, Hyman BT, Pak DT, Bu G, Rebeck GW. 2009. Interaction of reelin with amyloid precursor protein promotes neurite outgrowth. Journal of Neuroscience 29: 7459-7473. DOI: https://doi.org/10.1523/JNEUROSCI.4872-08.2009, PMID: 19515914

Hunter S, Brayne C. 2012. Relationships between the amyloid precursor protein and its various proteolytic fragments and neuronal systems. Alzheimer's Research \& Therapy 4:10. DOI: https://doi.org/10.1186/alzrt108, PMID: 22498202

Kaden D, Voigt P, Munter LM, Bobowski KD, Schaefer M, Multhaup G. 2009. Subcellular localization and dimerization of APLP1 are strikingly different from APP and APLP2. Journal of Cell Science 122:368-377. DOI: https://doi.org/10.1242/jcs.034058, PMID: 19126676 
Kang J, Lemaire HG, Unterbeck A, Salbaum JM, Masters CL, Grzeschik KH, Multhaup G, Beyreuther K, MüllerHill B. 1987. The precursor of Alzheimer's disease amyloid A4 protein resembles a cell-surface receptor. Nature 325:733-736. DOl: https://doi.org/10.1038/325733a0, PMID: 2881207

Liu T, Zhang T, Yu H, Shen H, Xia W. 2014. Adjudin protects against cerebral ischemia reperfusion injury by inhibition of neuroinflammation and blood-brain barrier disruption. Journal of Neuroinflammation 11:107. DOI: https://doi.org/10.1186/1742-2094-11-107

Müller UC, Zheng H. 2012. Physiological functions of APP family proteins. Cold Spring Harbor Perspectives in Medicine 2:a006288. DOI: https://doi.org/10.1101/cshperspect.a006288, PMID: 22355794

Mulligan KA, Cheyette BN. 2012. Wnt signaling in vertebrate neural development and function. Journal of Neuroimmune Pharmacology 7:774-787. DOl: https://doi.org/10.1007/s11481-012-9404-x, PMID: 23015196

Nicolas M, Hassan BA. 2014. Amyloid precursor protein and neural development. Development 141:2543-2548.

DOI: https://doi.org/10.1242/dev.108712, PMID: 24961795

Niehrs C. 2012. The complex world of WNT receptor signalling. Nature Reviews Molecular Cell Biology 13:767779. DOl: https://doi.org/10.1038/nrm3470

Ninomiya H, Roch JM, Sundsmo MP, Otero DA, Saitoh T. 1993. Amino acid sequence RERMS represents the active domain of amyloid beta/A4 protein precursor that promotes fibroblast growth. Journal of Cell Biology 121:879-886. DOl: https://doi.org/10.1083/jcb.121.4.879

Oishi I, Suzuki H, Onishi N, Takada R, Kani S, Ohkawara B, Koshida I, Suzuki K, Yamada G, Schwabe GC, Mundlos $\mathrm{S}$, Shibuya H, Takada S, Minami Y. 2003. The receptor tyrosine kinase Ror2 is involved in non-canonical Wnt5a/ JNK signalling pathway. Genes to Cells 8:645-654. DOI: https://doi.org/10.1046/j.1365-2443.2003.00662.x, PMID: 12839624

Ott MO, Bullock SL. 2001. A gene trap insertion reveals that amyloid precursor protein expression is a very early event in murine embryogenesis. Development Genes and Evolution 211:355-357. DOI: https://doi.org/10. 1007/s004270100158, PMID: 11466532

Panegyres PK, Atkins ER. 2011. The Functions of the Amyloid Precursor Protein Gene and Its Derivative Peptides: I Molecular Biology and Metabolic Processing. Neuroscience and Medicine 02:120-131. DOI: https:// doi.org/10.4236/nm.2011.22018

Parr C, Mirzaei N, Christian M, Sastre M. 2015. Activation of the wnt/ $\beta$-catenin pathway represses the transcription of the $\beta$-amyloid precursor protein cleaving enzyme (BACE1) via binding of T-cell factor-4 to BACE1 promoter. The FASEB Journal 29:623-635. DOI: https://doi.org/10.1096/fj.14-253211, PMID: 25384422

Perez RG, Zheng H, Van der Ploeg LH, Koo EH. 1997. The beta-amyloid precursor protein of Alzheimer's disease enhances neuron viability and modulates neuronal polarity. The Journal of Neuroscience 17:9407-9414. DOI: https://doi.org/10.1523/JNEUROSCI.17-24-09407.1997, PMID: 9390996

Pietrzik CU, Yoon IS, Jaeger S, Busse T, Weggen S, Koo EH. 2004. FE65 constitutes the functional link between the low-density lipoprotein receptor-related protein and the amyloid precursor protein. Journal of Neuroscience 24:4259-4265. DOI: https://doi.org/10.1523/JNEUROSCI.5451-03.2004, PMID: 15115822

Polleux F, Snider W. 2010. Initiating and growing an axon. Cold Spring Harbor Perspectives in Biology 2: a001925. DOI: https://doi.org/10.1101/cshperspect.a001925, PMID: 20452947

Preat T, Goguel V. 2016. Role of Drosophila amyloid precursor protein in memory formation. Frontiers in Molecular Neuroscience 9:142. DOI: https://doi.org/10.3389/fnmol.2016.00142, PMID: 28008309

Reinhard C, Hébert SS, De Strooper B. 2005. The amyloid-beta precursor protein: integrating structure with biological function. The EMBO Journal 24:3996-4006. DOI: https://doi.org/10.1038/sj.emboj.7600860, PMID: 16252002

Rossjohn J, Cappai R, Feil SC, Henry A, McKinstry WJ, Galatis D, Hesse L, Multhaup G, Beyreuther K, Masters $\mathrm{CL}$, Parker MW. 1999. Crystal structure of the nterminal, growth factor-like domain of alzheimer amyloid precursor protein. Nature Structural Biology 6:327-331. DOI: https://doi.org/10.1038/7562, PMID: 10201399

Rosso SB, Inestrosa NC. 2013. WNT signaling in neuronal maturation and synaptogenesis. Frontiers in Cellular Neuroscience 7:103. DOI: https://doi.org/10.3389/fncel.2013.00103, PMID: 23847469

Salbaum JM, Ruddle FH. 1994. Embryonic expression pattern of amyloid protein precursor suggests a role in differentiation of specific subsets of neurons. Journal of Experimental Zoology 269:116-127. DOI: https://doi. org/10.1002/jez.1402690205

Sarasa M, Sorribas V, Terradoa J, Climent S, Palacios JM, Mengod G. 2000. Alzheimer beta-amyloid precursor proteins display specific patterns of expression during embryogenesis. Mechanisms of Development 94:233236. DOl: https://doi.org/10.1016/S0925-4773(00)00297-5, PMID: 10842078

Selkoe DJ, Hardy J. 2016. The amyloid hypothesis of Alzheimer's disease at 25 years. EMBO Molecular Medicine 8:595-608. DOI: https://doi.org/10.15252/emmm.201606210, PMID: 27025652

Sellers KJ, Elliott C, Jackson J, Ghosh A, Ribe E, Rojo Al, Jarosz-Griffiths HH, Watson IA, Xia W, Semenov M, Morin P, Hooper NM, Porter R, Preston J, Al-Shawi R, Baillie G, Lovestone S, Cuadrado A, Harte M, Simons P, et al. 2018. Amyloid $\beta$ synaptotoxicity is Wnt-PCP dependent and blocked by fasudil. Alzheimer's \& Dementia 14:306-317. DOI: https://doi.org/10.1016/j.jalz.2017.09.008, PMID: 29055813

Shariati SA, De Strooper B. 2013. Redundancy and divergence in the amyloid precursor protein family. FEBS Letters 587:2036-2045. DOl: https://doi.org/10.1016/j.febslet.2013.05.026, PMID: 23707420

Shimizu K, Sato M, Tabata T. 2011. The Wnt5/planar cell polarity pathway regulates axonal development of the Drosophila mushroom body neuron. Journal of Neuroscience 31:4944-4954. DOI: https://doi.org/10.1523/ JNEUROSCI.0154-11.2011, PMID: 21451033

Small DH, Nurcombe V, Reed G, Clarris H, Moir R, Beyreuther K, Masters CL. 1994. A heparin-binding domain in the amyloid protein precursor of Alzheimer's disease is involved in the regulation of neurite outgrowth. The 
Journal of Neuroscience 14:2117-2127. DOI: https://doi.org/10.1523/JNEUROSCI.14-04-02117.1994, PMID: 8158260

Soldano A, Okray Z, Janovska P, Tmejová K, Reynaud E, Claeys A, Yan J, Atak ZK, De Strooper B, Dura JM, Bryja $V$, Hassan BA. 2013. The Drosophila homologue of the amyloid precursor protein is a conserved modulator of wnt PCP signaling. PLOS Biology 11:e1001562. DOI: https://doi.org/10.1371/journal.pbio.1001562, PMID: 236 90751

Soldano A, Hassan BA. 2014. Beyond pathology: app, brain development and Alzheimer's disease. Current Opinion in Neurobiology 27:61-67. DOI: https://doi.org/10.1016/j.conb.2014.02.003, PMID: 24632309

Southam KA, Stennard F, Pavez C, Small DH. 2019. Knockout of amyloid $\beta$ protein precursor (APP) Expression alters synaptogenesis, neurite branching and axonal morphology of hippocampal neurons. Neurochemical Research 44:1346-1355. DOI: https://doi.org/10.1007/s11064-018-2512-0, PMID: 29572646

Stahl R, Schilling S, Soba P, Rupp C, Hartmann T, Wagner K, Merdes G, Eggert S, Kins S. 2014. Shedding of APP limits its synaptogenic activity and cell adhesion properties. Frontiers in Cellular Neuroscience 8:410.

DOI: https://doi.org/10.3389/fncel.2014.00410, PMID: 25520622

Tapia-Rojas C, Burgos PV, Inestrosa NC. 2016. Inhibition of wnt signaling induces amyloidogenic processing of amyloid precursor protein and the production and aggregation of Amyloid- $\beta(A \beta)_{42}$ peptides. Journal of Neurochemistry 139:1175-1191. DOI: https://doi.org/10.1111/jnc.13873, PMID: 27778356

Vagnozzi AN, Praticò D. 2019. Endosomal sorting and trafficking, the retromer complex and neurodegeneration. Molecular Psychiatry 24:857-868. DOl: https://doi.org/10.1038/s41380-018-0221-3, PMID: 30120416

van der Kant R, Goldstein LS. 2015. Cellular functions of the amyloid precursor protein from development to dementia. Developmental Cell 32:502-515. DOI: https://doi.org/10.1016/j.devcel.2015.01.022, PMID: 25710536

Wong HH, Lin JQ, Ströhl F, Roque CG, Cioni JM, Cagnetta R, Turner-Bridger B, Laine RF, Harris WA, Kaminski CF, Holt CE. 2017. RNA docking and local translation regulate Site-Specific axon remodeling in Vivo. Neuron 95:852-868. DOI: https://doi.org/10.1016/j.neuron.2017.07.016, PMID: 28781168

Young-Pearse TL, Chen AC, Chang R, Marquez C, Selkoe DJ. 2008. Secreted APP regulates the function of fulllength APP in neurite outgrowth through interaction with integrin beta1. Neural Development 3:15. DOI: https://doi.org/10.1186/1749-8104-3-15, PMID: 18573216

Yuksel M, Tacal O. 2019. Trafficking and proteolytic processing of amyloid precursor protein and secretases in Alzheimer's disease development: An up-to-date review. European Journal of Pharmacology 856:172415. DOI: https://doi.org/10.1016/j.ejphar.2019.172415, PMID: 31132354 